\title{
Multisheet modelling of the electrical conductivity structure in the Fennoscandian Shield
}

\author{
Martin Engels ${ }^{1}$, Toivo Korja ${ }^{2}$, and the BEAR Working Group \\ ${ }^{1}$ Department of Earth Sciences, Geophysics, Uppsala University, Villavägen 16, SE-75646 Uppsala, Sweden \\ ${ }^{2}$ Academy of Finland/University of Oulu/Geological Survey of Finland, POB 96, FIN-02151, Espoo, Finland
}

(Received December 31, 2000; Revised July 30, 2001; Accepted August 13, 2001)

\begin{abstract}
Electromagnetic multisheet modelling is a powerful tool for large model areas, if they can be approximated by a multilayered heterogeneous conductivity structure of small vertical dimension in comparison with the penetration depth of electromagnetic fields. In this paper, thin sheet technique is applied to the whole Fennoscandian (Baltic) Shield, whose upper mantle conductivity structure is the objective of the long period electromagnetic array experiment BEAR (Baltic Electromagnetic Array Research). Three thin sheets, each of about 120,000 model cells with the base length of $10 \mathrm{~km}$, describe a-priori crustal inhomogeneities in terms of conductances. The three sheets represent i) upper crust from surface to the depth of $10 \mathrm{~km}$ including continental and ocean bottom sediments and seawater, ii) middle crust ranging from $10 \mathrm{~km}$ to $30 \mathrm{~km}$ and iii) lower crust from $30 \mathrm{~km}$ to $60 \mathrm{~km}$. Thus, modelling is taking into account distortions caused by crustal conductivity anomalies. Additionally, distortions due to inhomogeneous external current systems are investigated by introducing an equivalent current system of a polar electrojet model at ionosphere height. Modelling results are illustrated by induced current distribution at different depth levels and by various electromagnetic transfer functions. The latter demonstrate the resolution of crustal conductivity anomalies and their screening effect even at long periods. The predicted behavior of transfer functions in the very complex conductivity structure is compared with the experimental BEAR data, showing qualitatively a first order agreement for most of the sites. Modeled phases for periods of a few thousands of seconds are considerably biased in comparison with experimental data if the background 1-D model has monotonously decreasing resistivity. However, the bias from phases is removed if a conducting asthenosphere having a resistivity of $20 \Omega \mathrm{m}$ is emplaced between the depths of $200 \mathrm{~km}$ and $300 \mathrm{~km}$. Thus, multisheet modelling indicates a well conducting upper mantle under the Fennoscandian Shield. All modelling has been performed using a multisheet code by Avdeev, Kuvshinov and Pankratov.
\end{abstract}

\section{Introduction}

The BEAR project is an integral part of Europrobe's (a lithosphere dynamics program of the European Science Foundation) SVEKALAPKO project (Hjelt and Daly, 1996), standing for a transect through the Palaeoproterozoic SVEcofennian orogen, the Archaean KArelian craton and the Palaeoproterozoic LAPland KOla orogen. The Archaean and Palaeoproterozoic origin and evolution of the Fennoscandian Shield is the objective of this multidisciplinary research program. The BEAR subproject realises an international experiment for deep electromagnetic sounding of the ancient Fennoscandian Shield. Using a shield wide magnetotelluric and magnetometer array of simultaneous long period recordings, the electrical conductivity structure of the lithosphere-asthenosphere system is one key target for investigations.

This experiment, however, is faced with two difficulties: source effects from polar regions and distortions caused by heterogeneous crustal conductivity structure. Multisheet modelling can simultaneously investigate both types of distortions. Crustal heterogeneities are described by an earth

Copy right (C) The Society of Geomagnetism and Earth, Planetary and Space Sciences (SGEPSS); The Seismological Society of Japan; The Volcanological Society of Japan; The Geodetic Society of Japan; The Japanese Society for Planetary Sciences. model containing three thin sheets; inhomogeneous sources are represented by the source model of an equivalent current system in a sheet. The main aims of this paper are to use multisheet modelling for an understanding of long period electromagnetic responses in the whole shield in presence of heterogeneous crustal structure and optional non-uniform sources. In particular, we aim (1) to investigate distortions caused by crustal conductors based on the use of numerous a-priori information, (2) to investigate distortions in transfer functions caused by non-uniform source field i.e. to compare plane wave and a polar electrojet prototype, (3) to compare multisheet modelling results with experimental BEAR data.

The design of the BEAR array is introduced in Fig. 1. Circles indicate temporal five component magnetotelluric sites (B01 to B50) and triangles permanent magnetometer stations (A01 to A23). Simultaneous magnetotelluric recordings were carried out for almost two months during summer 1998 with a sampling rate of $2 \mathrm{~s}$ yielding electromagnetic transfer functions in a period range from about $10 \mathrm{~s}$ to $100,000 \mathrm{~s}$. At magnetometer sites continuous recordings have been made since several years in the frame of IMAGE and SAMNET projects (e.g. Viljanen and Häkkinen, 1997). These sites in Fennoscandia make up the main part of the BEAR array with a size of ca. $1200 \mathrm{~km}$ (NS direction $) \times 1000 \mathrm{~km}(\mathrm{EW})$. Five additional sites are located 


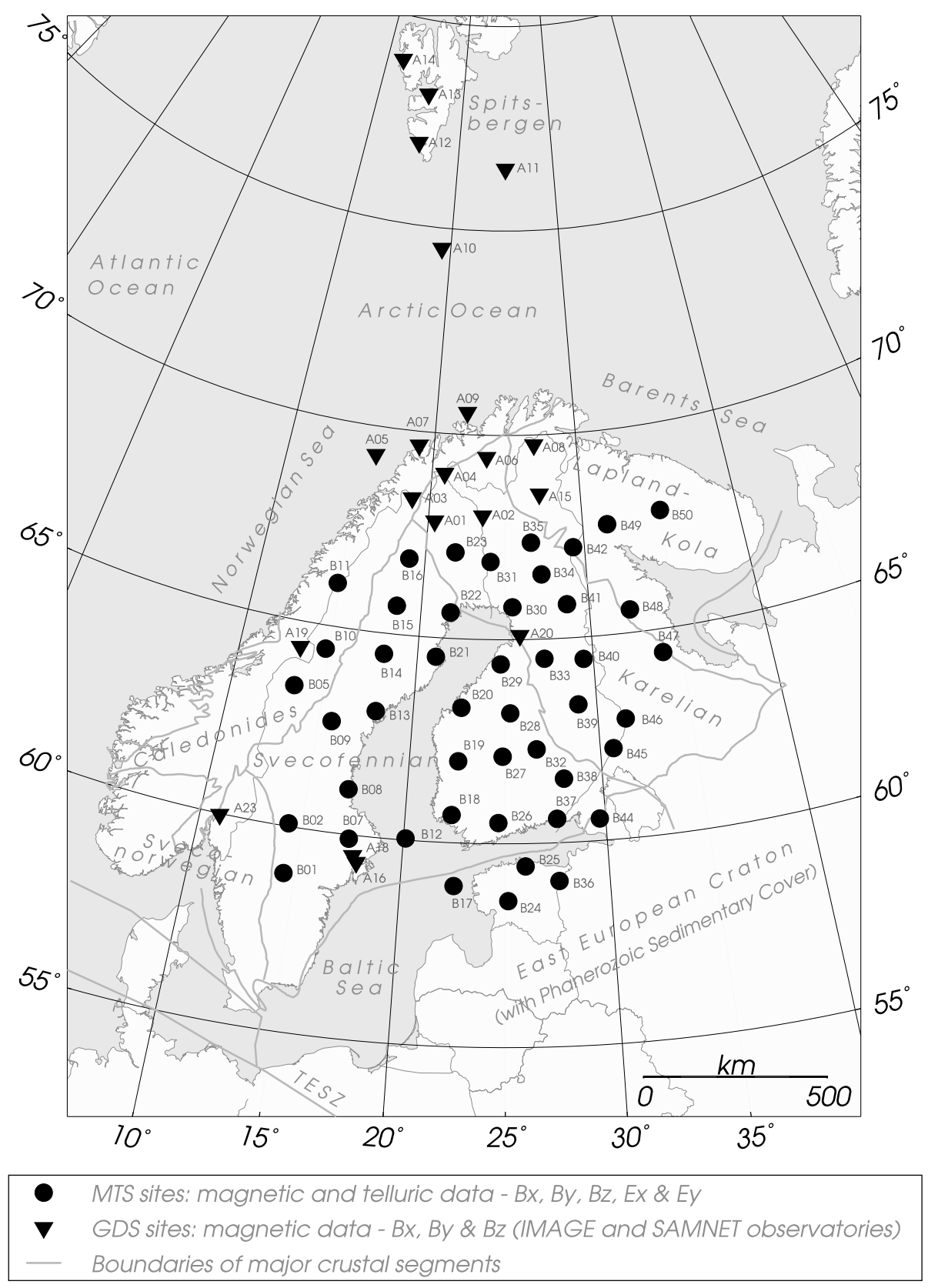

Fig. 1. The BEAR array used for ultra-deep electromagnetic sounding to probe electrical properties of the upper mantle beneath Fennoscandia. Boundaries of major crustal units are from Gorbatschev and Bogdanova (1993). TESZ stands for Trans-European Suture Zone and it separates the Precambrian East European Craton (Fennoscandia, Sarmatia and Volgo-Uralia) from the Phanerozoic Central Europe.

further north on the islands of Spitzbergen and Bear Island in the Barents Sea. These stations cover the whole polar oval and allow monitoring external source current systems. The BEAR site positions on an irregular grid have been selected carefully in order to avoid known conductors and cultural noise. The average site spacing of about $150 \mathrm{~km}$ is designed for resolving the upper mantle target depth of an assumed lithosphere-asthenosphere boundary.

Various geoelectromagnetic studies-e.g. profile transects such as SVEKA (Korsman et al., 1999; Korja and Koivukoski, 1994), POLAR (Korja et al., 1989), FENNOLORA (Rasmussen et al., 1987), Värmland (Rasmussen, 1988), Jämtland (Gharibi et al., 2000), Murmansk-Viborg (Kovtun et al., 1998) or magnetometer arrays (e.g. Pajunpää, 1987, 1989; Jones, 1981, 1983)have been carried out during the last two decades, reviewed by Korja and Hjelt $(1993,1998)$ and Korja (1997) with comprehensive lists of references. In contrast to the BEAR project, previous investigations are mostly crustal studies with low resolution for mantle depth. The Fennoscandian Shield is a challenging natural laboratory: It hosts prominent conductivity anomalies with conductances of thousands of Siemens, which seriously screen structures beneath. Often, anomalies are shaped as highly conductive belts associated with graphite- and sulphide-bearing metasediments, tracing former tectonic processes. On the other hand, a cover of sedimentary rocks is practically missing. The shield contains areas of extremely resistive crust (less than 1 Siemens), 
which works as a transparent window into the deep Earth and makes soundings down to the deep lithosphere and beyond feasible.

At high latitudes of Fennoscandia the vicinity of dynamic polar current systems in ionosphere and magnetosphere temporarily gives rise to inhomogeneous source field conditions. If non-uniform external electromagnetic fields enter response functions, they become biased and do not describe any more purely the internal system Earth. Source effects have been studied in Fennoscandia (e.g. Osipova $e t$ al., 1989; Pirjola, 1992; Viljanen, 1996) and elsewhere (e.g. Mareschal, 1986; Garcia et al., 1997). Often, source effects are modeled by single event studies representing typical source field configurations. In contrast, source effects in processed data are usually observed in transfer function estimates, which are based on certain stacking procedures, 'averaging' (possibly constructive) events of quasi-uniform and dynamic inhomogeneous sources.

Multisheet forward modelling is able to model the combination of both types of distortions because both, the crustal anomalies and the inhomogeneous sources, can be taken simultaneously into account. This is achieved by the use of several sheets that describe the complex crustal conductivity structure in the Earth and the external current system at source level altitude. In contrast to the computational limitations in volume 3-D modelling, thin sheet modelling is the only tool to realise large areas with a fine model grid (here 120,000 model cells with $10 \mathrm{~km}$ base length). This discretisation allows to describe well the regional-scale conductivity structures, the model area 10 times larger than the BEAR-array allows to avoid artificial boundary effects. The 'price to pay' is the simplification of the earth model, which consists of lateral heterogeneous sheets with no vertical dimension, embedded in an otherwise uniform 1-D structure. However, for electromagnetic penetration depths well into the Earth's mantle, the thin sheet approximation can be justified. Forward modelling allows testing hypothetical conductivity structures by comparison with experimental data. Besides, synthetic multisheet data can be used for testing the validity and efficiency of 1-D and 2-D inversion codes applied to real BEAR data. Synthetic electromagnetic fields can also provide boundary fields as starting values for upcoming volume 3-D inversion. Previous thin sheet efforts in Fennoscandia are regional studies aimed to model the crustal structure, e.g. Vanyan et al. (1989), Yegorov et al. (1983), Vanyan and Kouznetsov (1999) and review by Kaikkonen (1998).

\section{Numerical Multisheet Modelling}

The thin sheet modelling introduced in this paper has been performed using the XPLATES code by Avdeev, Kuvshinov, and Pankratov. In contrast to former standard single sheet codes (cf. Vasseur and Weidelt, 1977; Dawson and Weaver, 1979, extended by McKirdy et al., 1985), XPLATES calculates the electromagnetic fields for an earth model of several thin sheets embedded in a 1-D normal formation, excited either by plane wave or by arrays of magnetic or electric dipoles. The code is based on a novel approach proposed in Avdeev et al. (2000). This approach combines a modern Krylov subspace iteration (cf. Greenbaum, 1997) with the modified iterative dissipative method (MIDM; Singer, 1995, extended by Pankratov et al., 1995, 1997 and Singer and Fainberg, 1995, 1997). In MIDM, the conventional scattering equation is modified to a scattering equation with a contracting kernel, which is then solved iteratively in equivalence to Neumann series summation. This method has been applied recently to a variety of multisheet (Pankratov, 1991) and volume 3-D (Avdeev et al., 1997, 1998, 1999; Kuvshinov et al., 1999; Singer et al., 1999; Zhdanov et al., 1999) problems. By replacing the Neumann series summation with Krylov subspace iteration, significant improvement of convergence has been reported in Avdeev et al. (2000), resulting in a solution acceleration of about one order of magnitude. Fast convergence made it possible to run the multisheet model of Fennoscandia as it is introduced in this paper.

The thin sheet technique replaces a volume layer by a thin sheet, which follows the boundary condition (originally Price, 1949)

$$
[\hat{\mathbf{z}} \times \mathbf{H}]_{-}^{+}=\tau \mathbf{E}_{s}=\mathbf{j}_{s} .
$$

The jump of the horizontal magnetic field $\left(H_{x}, H_{y}\right)$ across the upper $(-)$ and lower $(+)$ sheet surface corresponds to the sheet current density $\mathbf{j}_{s}$, the product of conductance $\tau$ and the electric field $\mathbf{E}_{s}$ within the sheet. This concept is based on a continuity of the electric field across the thin layer $\left(\left[\mathbf{E}_{\mathbf{s}}\right]_{-}^{+}=0\right.$ and $\left.\left[H_{z}\right]_{-}^{+}=0\right)$. Thus the electric field and vertical magnetic field is kept constant and the horizontal magnetic field varies linearly with depth within the sheet itself. The validity of this approximation can be expressed by a thin sheet condition (e.g. Singer and Fainberg, 1985, note also Weaver, 1994, Schmucker, 1995),

$$
\alpha \ll \min \left\{S,\left|C^{+}\right|,\left|C_{\tau}\right|\right\} .
$$

Parameter $\alpha$ stands for the dimension of the sheet, both the vertical thickness and the horizontal grid cell discretisation. $S$ is the length-scale of typical structural heterogeneities, $\left|C^{+}\right|$the scale length of penetration in the underlying section expressed by Schmucker's $C$-response (Schmucker, 1970) and $\left|C_{\tau}\right|=\left(\omega \mu_{0} \tau\right)^{-1}$ the scale length of penetration in the thin sheet itself (angular frequency $\omega=2 \pi / T$, period $T$, free space permeability $\mu_{0}$, and $\tau=\tau_{\max }$ as maximal conductance occurring in the sheet). $\left|C_{\tau}\right|$ is the difference of the vertical wavenumber $1 / C^{-}$above and $1 / C^{+}$below the sheet. Thus, the grid cell discretisation must be denser than the scale-length of lateral conductivity inhomogeneities, the grid cell dimensions shall be small in relation to the scale of penetration depth and the penetration in the substratum shall be large in relation to the sheet dimensions. In other words, electromagnetic responses can vary only slightly across grid cells and the structure below must be resistive enough to allow further penetration in the substratum.

Keeping the thickness of the thin sheet in the model sufficiently small (often zero, here $100 \mathrm{~m}$ ), usually the discretisation of grid cells (here $10 \mathrm{~km}$ ) is the limiting factor. In the modelling of the Fennoscandian Shield, an upper bound of maximal conductance has been set to 10,000 Siemens, limiting very few larger anomalies in the shield to this value. In Table 1 scale lengths relevant for the thin sheet condition are listed. Periods shorter than tens of minutes start 
Table 1. For a maximal conductance $\tau$ of 10,000 Siemens, scale length $\left|C_{\tau}\right|[\mathrm{km}]$ is listed for those periods $T[\mathrm{~s}]$ used by multisheet modelling. If periods are longer than several minutes, $\left|C_{\tau}\right|$ is larger than the grid cell base length of $10 \mathrm{~km}$. For a conductance $\tau$ of 1,000 Siemens, corresponding values of $\left|C_{\tau}\right|$ multiply by factor 10 . The scale length of penetration $\left|C_{i}\right|[\mathrm{km}]$ in the rather resistive substratum below the three sheets $(i=1,2,3)$ is not critical for the thin sheet approximation.

\begin{tabular}{rrrrr}
\hline \multicolumn{1}{c}{$\mathrm{T}$} & \multicolumn{1}{c}{$\left|C_{\tau}\right|$} & $\left|C_{1}^{+}\right|$ & $\left|C_{2}^{+}\right|$ & $\left|C_{3}^{+}\right|$ \\
\hline 128 & 3.2 & 139.6 & 122.4 & 104.0 \\
256 & 6.5 & 169.4 & 151.9 & 132.4 \\
512 & 13.0 & 202.5 & 184.8 & 164.5 \\
1024 & 25.9 & 245.1 & 227.4 & 206.8 \\
2048 & 51.9 & 301.5 & 283.7 & 262.5 \\
4096 & 103.8 & 364.6 & 346.4 & 324.6 \\
8192 & 207.5 & 438.4 & 420.0 & 397.6 \\
16384 & 415.0 & 517.7 & 498.9 & 475.6 \\
32768 & 830.0 & 584.0 & 564.7 & 540.9 \\
65536 & 1660.0 & 634.0 & 614.6 & 590.5 \\
\hline
\end{tabular}

to violate the strict thin sheet condition for $\left|C_{\tau}\right|$, becoming smaller than $10 \mathrm{~km}$. However, note that the condition refers to the maximal conductance- the thin sheet approximation becomes inaccurate in areas of extreme conductances first, but might still be a rough approximation — while other areas remain reliable.

Additionally, a discretisation test has been performed: For a test conductance model of the Fennoscandian Shield with quadratic grid cells of base length $40 \mathrm{~km}$, cells have been subdivided further into 4 cells of $20 \mathrm{~km}$ base length and 16 cells of $10 \mathrm{~km}$ base length, successively. Thus, an identical earth model but with different grid cell discretisation has been used. Comparing the electromagnetic fields along various profiles crossing the main conductor belts, $10 \mathrm{~km}$ grid cell size was found to be a sufficient discretisation. Differences become significant only rarely at extreme conductivity contrasts. There, the cell centres of two cells describing a huge jump in conductivity are closer to the conductance contrast for a finer grid than those of a coarse grid. Anomalous fields change discontinuously at conductivity contrasts due to electric charges (B-polarisation), consequently differences are expected if cell centres come closer to the contrast. Responses close to extreme conductivity contrasts are proceeded with caution.

The model area is surrounded by a homogeneous layerin case of the first sheet by a shallow ocean of 2,000 Siemens, which corresponds to the average conductance of the outer grid cells, mainly ocean and thick sediments. The model area of interest shall be extended by theoretically $L=\sqrt{\tau_{\max } R^{t}} \mathrm{~km}$ to guarantee a complete decay of anomalous fields (with $R^{t}$ as transversal resistivity of the underlying section). This rule results in about $2,000 \mathrm{~km}$ distance due to the quite resistive normal structure (see Table 2). Practically, the model area has been extended stepwise, starting from an area of $216 \times 240$ cells $(\mathrm{EW} \times \mathrm{NS})$ with sizes of $10 \times 10 \mathrm{~km}^{2}$, represented in several figures (3-7). Compared with the dimensions of the BEAR array of $1000 \times 1200 \mathrm{~km}$
Table 2. Resistivities in $\Omega \mathrm{m}$ of the standard normal model used for multisheet modelling based on Korja et al. (2002). Three heterogeneous thin sheets are embedded in the crustal part of the model at $0 \mathrm{~km}, 20 \mathrm{~km}$ and $45 \mathrm{~km}$ depth.

\begin{tabular}{cc}
\hline Depth $[\mathrm{km}]$ & Resistivity $[\Omega \mathrm{m}]$ \\
\hline 0 & $(1$. SHEET $)$ \\
$0-10$ & 20,000 \\
$10-20$ & 10,000 \\
20 & $(2$. SHEET $)$ \\
$20-45$ & 3,000 \\
45 & $(3$. SHEET $)$ \\
$45-60$ & 2,000 \\
$60-100$ & 1,000 \\
$100-200$ & 300 \\
$200-400$ & 100 \\
$400-600$ & 20 \\
$600-800$ & 2 \\
$800-1200$ & 5 \\
$1200-\infty$ & 0.5 \\
\hline
\end{tabular}

$(\mathrm{EW} \times \mathrm{NS})$, the distance between magnetotelluric sites and the boundary of the model area is at least $600 \mathrm{~km}$. While increasing the model area by additional surrounding cells, changes of responses at BEAR sites have been observed. A frame of 60 additional cells was found to guarantee stable responses, resulting in a model area of $336 \times 360$ cells $(\mathrm{EW} \times \mathrm{NS})$ and a minimum spacing of $1,200 \mathrm{~km}$ between the boundary of the anomalous domain and the sites. Thus, an area 10 times larger than the BEAR array was found to provide synthetic BEAR responses being practically independent from the boundary of the sheet.

The stopping criterion for the iteration process is the relative residual norm. Setting this threshold parameter too generous, say $1 \%$, response functions start to become scattered, which is visible first at single frequencies and in very local regions. The threshold has been decreased stepwise to $0.02 \%$ guaranteeing stable responses over the whole shield. A control of the response function behaviour for various locations turned out to be an effective test for stability.

Finally, it shall be remarked that thin sheet modelling is always a trade off between the particular demands of the model target and limitations of numerical modelling (including convergence, memory and run time). The huge model area of 120,960 model cells in each of three thin sheets and the source level as well as the maximum conductivity contrasts of 100,000 in a rather complex conductivity structure resulted in a run time of about 1.5 hours per frequency and polarisation for the strict residual threshold of $0.02 \%$ on a conventional $450 \mathrm{MHz}$ PC.

\section{Fennoscandian Shield Earth Model and Elec- trojet Source Model}

The concept of the Fennoscandian multisheet model is sketched in Fig. 2. Input parameters describe the earth and the source model, output quantities are the electromagnetic 

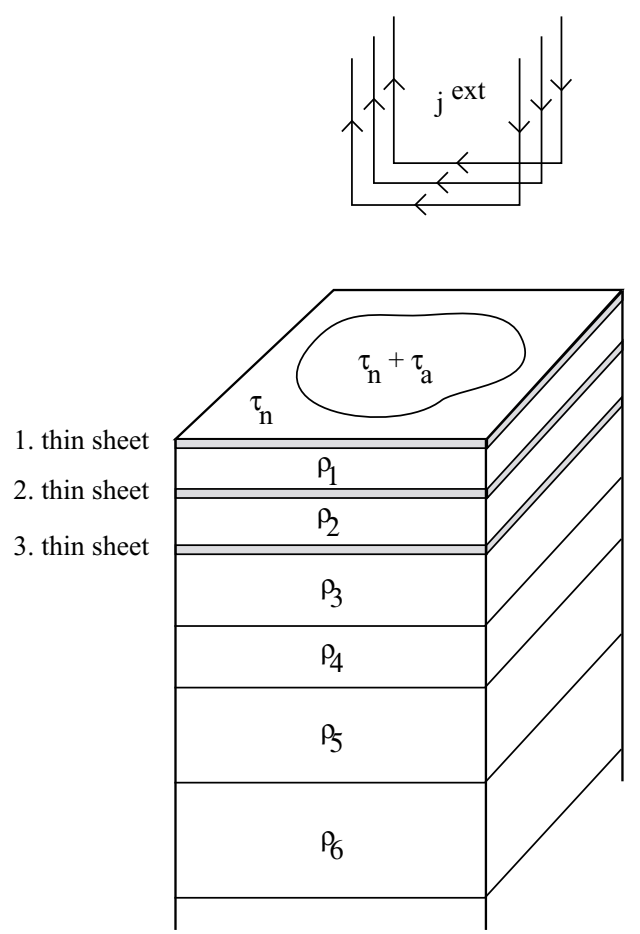

Fig. 2. The earth model of the Fennoscandian Shield consists of three thin sheets embedded in a 1-D host structure, indicated by resistivities $\rho_{i}(i=1,2, \ldots)$. Each thin sheet describes lateral inhomogeneities by variable conductances $\tau_{a}$ in grid cells of the anomalous domain, superimposed to the normal sheet conductance $\tau_{n}$. The polar electrojet source model is sketched by the external current density $j^{\text {ext }}$ forming parallel current loops.

fields at selected observation levels.

The earth model is based on a-priori information from the Fennoscandian Shield. Results from various field campaigns of the last two decades, for instance magnetotelluric, magnetovariational, airborne magnetic data and geological information have been compiled by Korja (Korja et al., 2002, this volume) into a shield-wide conductivity model. 1-D normal models for separate parts of the shield fill gaps (see Korja et al., 2002, for details and references). The resulting crustal model consists of six layers, each having a thickness of $10 \mathrm{~km}$. This unique digital database is used in this paper as a-priori conductance information by transforming the 6-layer conductivity model into thin sheets. Three sheets with lateral inhomogeneous conductances represent the upper, middle and lower crust of the multisheet earth model. The top sheet at the Earth's surface represents the upper $10 \mathrm{~km}$. The second sheet at $20 \mathrm{~km}$ depth contains inhomogeneities of the middle crust from $10 \mathrm{~km}$ to $30 \mathrm{~km}$, and the lower sheet at $45 \mathrm{~km}$ depth covers the depth range from $30 \mathrm{~km}$ to $60 \mathrm{~km}$. These sheets are embedded in a layered 1-D normal model, which is derived as an approximate average from available normal models of Fennoscandia. The use of several sheets shall roughly approximate the vertical dimension of conductors, attracting vertical currents between 'slices' of anomalies if sheets are close. For instance, dipping anomalies (e.g. Skellefteå in northern Sweden) that extend over the whole crust are imaged in each of the three sheets, indicating the dip angle to the north by the consequent shift of the anomaly position northwards in deeper sheets.

Figure 3 illustrates the conductance distribution of these three sheets, namely the i) upper crust including seawater as well as sea and continental sediments and ii) middle crust and iii) lower crust. An area represented by $216 \times 240$ squared cells with a base length of $10 \mathrm{~km}$ is shown and indicated at the lower and left axis, while geographic coordinates are annotated at the upper and right axis. Note that the total model area of $336 \times 360$ model cells exceeds the plotted area by $600 \mathrm{~km}$ in each coordinate direction. Conductances do vary in a wide range covering 5 decades. The Baltic Shield is surrounded by well conducting seawater and sea sediments to the north and west and thick sediments in the East European Platform and northern Variscides. The shield itself consists, on the one hand, of highly resistive crust, often only a few Siemens in total conductance, but on the other hand, the shield hosts highly conducting belts of graphite or sulphide bearing metasediments. Those conductive belts are possibly signatures of previous tectonic processes (Korja, 1997). One belt extends from the Caledonides via Sweden (Storavan-Skellefteå) and Finland (Bothnian and Southern Finland) into the Russian platform (Lake Ladoga). Other striking conductors are the Oulu conductor next to the northern Bothnian Bay and conductors associated with the Lapland Granulate Belt and the Central Lapland Schist Belt in the very north. Note that the conductance map is slightly smoothed due to filtering during inter- and extrapolation process. The conductor in the Bothnian Bay, linking Swedish and Finnish anomalies is strongly indicated but still remains speculative (Korja et al., 2002). There are only a few indications on the presence of the lower crustal anomalies but this may be due to the fact that only a few investigations have probed the structures at these depths. New measurements as well as BEAR project may indicate more lower crustal conductors.

The normal model, that forms host structure for embedded thin sheets, has to be assigned. Table 2 lists standard values used in this paper, which were obtained by an approximate average of various 1-D models derived for different parts of the shield (table 2 in Korja et al., 2002). Several alternative models have been tested and, in particular, a model which included an asthenospheric layer between the depths of $200 \mathrm{~km}$ and $300 \mathrm{~km}$ having a resistivity of $20 \Omega \mathrm{m}$ (see Section 5). In order to minimise extremes at observation sites located on top of prominent conductors (resembling a 'short cut'), the first sheet representing the upper $10 \mathrm{~km}$ inhomogeneities has been buried down to the depth of $5 \mathrm{~km}$ in another alternative model. This can be motivated for the shield area, because upper crustal conductors are mostly covered by a resistive overburden. The thickness of the 'overburden' with a resistivity of $20,000 \Omega \mathrm{m}$ itself is less important, electromagnetic fields penetrate almost unattenuated and the sheet represents a kind of average conductance over the depth range. At the same time, exposed sediments and seawater are shifted down to an unrealistic model depth. Yet the differences turn out to be small except for a few locations on top of strong anomalies.

The source model applied is either plane wave excitation in two polarisations or an inhomogeneous source represented by arrays of electrical dipoles. The 3-D current 


\section{Conductance: $\mathbf{0 - 1 0 ~} \mathrm{km}$}

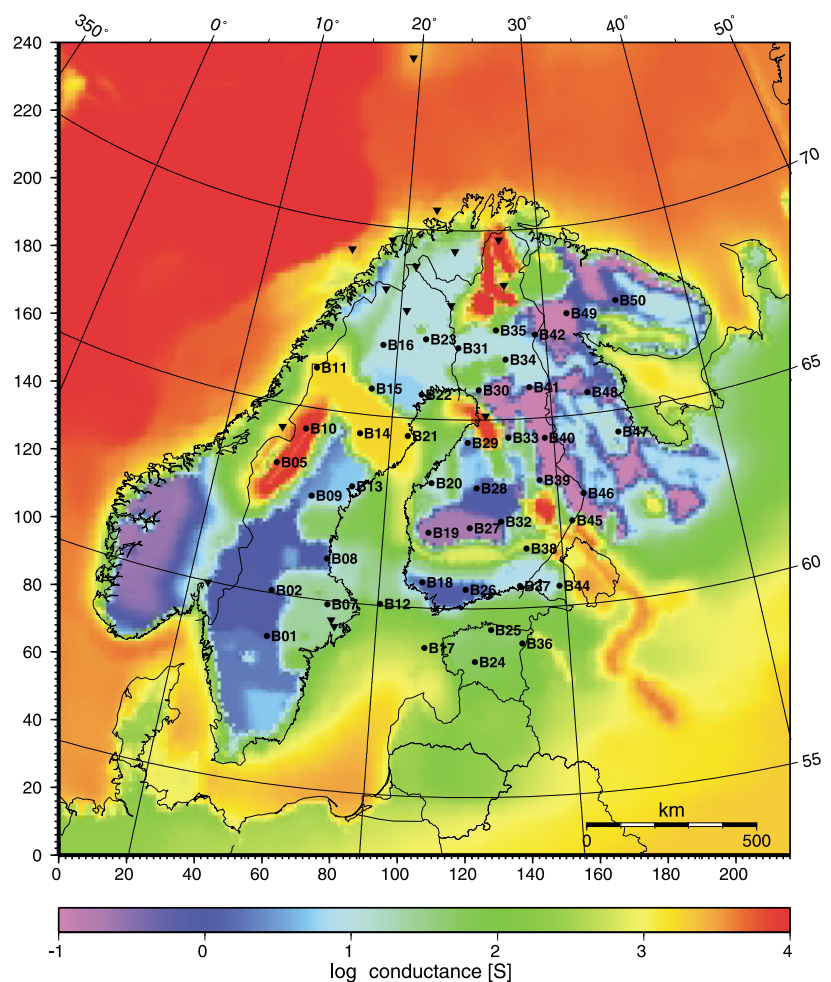

Fig. 3(a). The conductance of the surface sheet contains the conductance of sea water, sediment and upper crust $(0 \mathrm{~km}-10 \mathrm{~km})$.

\section{Conductance: $10-30 \mathrm{~km}$}

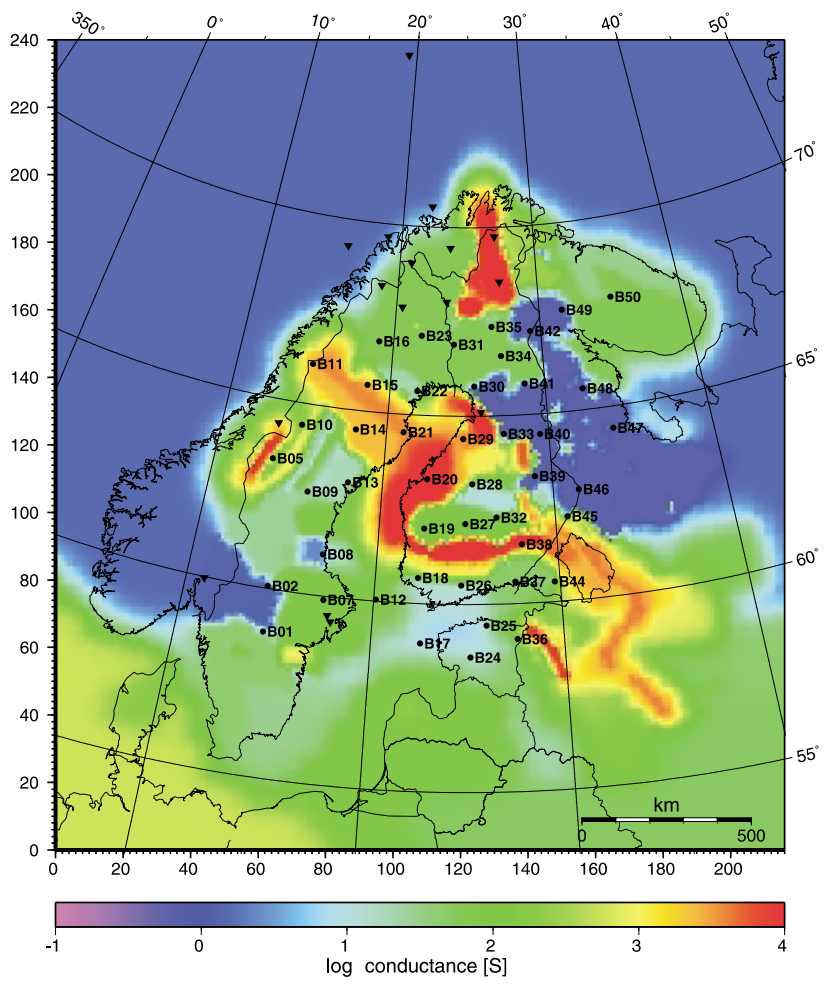

Fig. 3(b). The conductance of the second sheet represents the middle crust $(10 \mathrm{~km}-30 \mathrm{~km})$. Conductances vary in the range from 0.1 to 10,000 Siemens and are based on the conductance maps compiled by Korja et al. (2002). Abscissa and ordinate units represent model cells of $10 \mathrm{~km}$ base length.

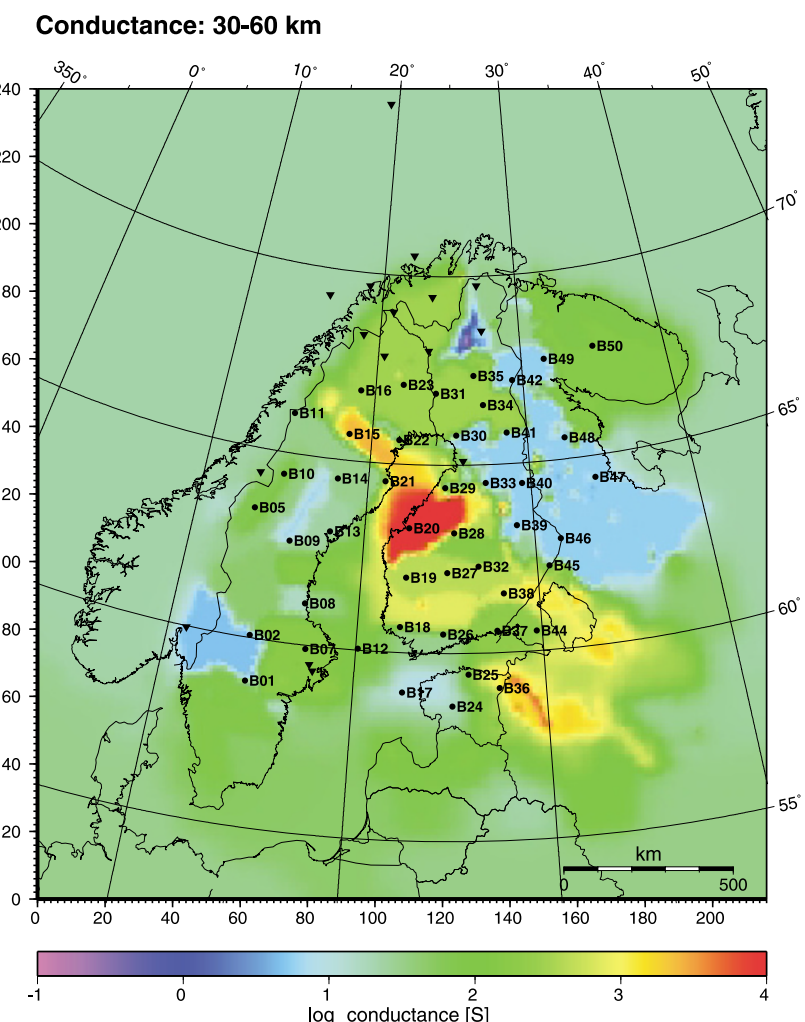

Fig. 3(c). The conductance of the third sheet represents the lower crust (30 $\mathrm{km}-60 \mathrm{~km})$

model, used here for a polar electrojet prototype description, consists of elementary current loop elements (with a Gaussian shaped current density distribution perpendicular to the jet axis). Each ' $U$ '-shaped current loop connects the horizontal ionospheric jet currents with vertical field aligned currents into the magnetosphere. The corresponding equivalent current model of Fig. 4, represented by electrical dipoles in a plane at the height of $110 \mathrm{~km}$, substitutes this physical 3-D current model. The former current pattern with vertical field aligned currents are expressed now by return currents in the equivalent sheet, but producing the same magnetic field on ground (Fukushima, 1971, 1976). Every equivalent current model produces exactly the same electromagnetic responses on ground as the original 3-D system, assuming zero conductivity in the atmosphere. For induction purposes in the Earth, equivalent current systems provide a convenient and complete description for the inducing field. The dense grid cell spacing $(10 \mathrm{~km})$ of electric dipoles in the ionospheric E-layer at the height of $110 \mathrm{~km}$ guarantees an almost exact approximation of the sheet current densities. The current source model of Fig. 4 represents a simplified prototype of a polar electrojet having a length of $1000 \mathrm{~km}$. The current density perpendicular to the jet axis (of the current loop model) has a Gaussian distribution with a half-width of $200 \mathrm{~km}$. Thus the source model corresponds to a superposition of many parallel current loops to describe also the decay. In contrast to simplified line or band current electrojet models, this current model is taking into account the finite extension of the jet. The model also takes into account the current loop geometry indirectly via the equivalent current 


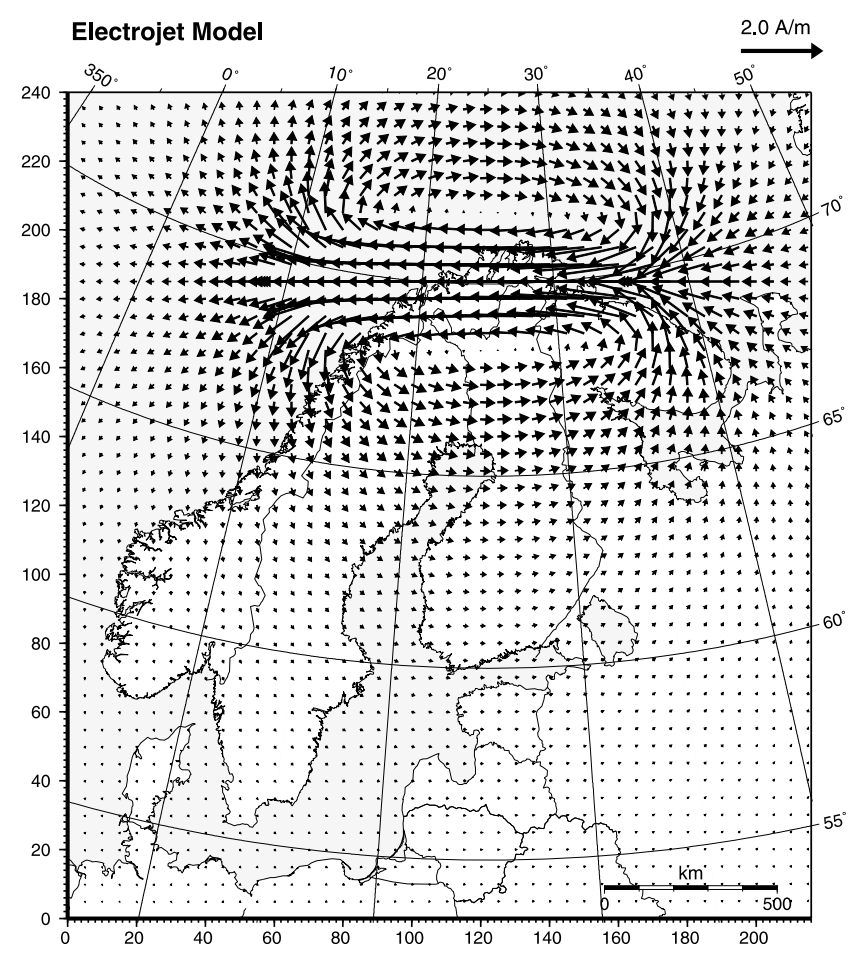

Fig. 4. Vectors indicate the current density in $\mathrm{A} / \mathrm{m}$ of the equivalent current system for a polar electrojet prototype at $110 \mathrm{~km}$ height. The westward electrojet extends over $1000 \mathrm{~km}$ along the jet axis with a Gaussian current distribution (half width of $200 \mathrm{~km}$ ) perpendicular to the jet axis. The physical model of superimposed current loop elements with vertical currents into the magnetosphere (e.g. Fig. 2) is replaced by return currents in the equivalent current sheet, producing the same electromagnetic fields on ground. Abscissa and ordinate units represent model cells of $10 \mathrm{~km}$ base length.

system. The source model is centred at $(70 \mathrm{~N}, 25 \mathrm{E})$ above the northern tip of Scandinavia. This location is roughly above and parallel to the coast, forces induced currents to the north of the jet axis to flow in conductive seawater while induced currents to the south of the jet axis penetrate the Baltic Shield. It should be noted, however, that the source model geometry is static - time dependence is restricted to a harmonic variation of the current density. Dynamic running sources may result in quite different responses, possibly including constructive or destructive averaging. Note that the current models for pulsations are also current loops with certain drift velocities. Different are the dimensions which increase with period. For Pc5 pulsations, the geometry of the source model introduced above is an acceptable approximation, too.

\section{Results of Modelling}

In this section, numerical results for (1) modelling with plane wave excitation and (2) modelling with the polar electrojet source are described.

For a period of $2048 \mathrm{~s}$ and excitation by EW-polarisation, implying an external magnetic field along the northsouth direction and favouring induced currents towards east, Fig. 5 illustrates the horizontal induced sheet current density. Vectors indicate the real part of current densities within the first, second and third sheet at the depth of $0 \mathrm{~km}, 20 \mathrm{~km}$ and $45 \mathrm{~km}$ (compare with Fig. 3), respectively. The inducing external electric field is scaled to $1 \mathrm{~V} / \mathrm{m}$. High seawater and sediment conductances host the main part of induced currents in the top sheet, but crustal conductors do also channel currents. Strong coast effects are indicated by the abrupt contrast at shield-ocean transition, while the increase of induced currents into the sedimentary cover in the south and east is more gradual. At the depth of $20 \mathrm{~km}$ (second sheet in Fig. 5), induced currents follow the elongated bands of mid-crustal conductors. Lower crustal currents are less concentrated and their absolute values decreased considerably as a consequence of screening electromagnetic fields by the conducting layers above.

The local magnetic transfer function $(\mathrm{A}, \mathrm{B})$ between the vertical $\left(B_{z}\right)$ and horizontal $\left(B_{x}\right.$ and $\left.B_{y}\right)$ magnetic flux density at one station is defined as (time dependence $e^{i \omega t}$ )

$$
B_{z}(\omega)=\mathrm{A}(\omega) B_{x}(\omega)+\mathrm{B}(\omega) B_{y}(\omega)
$$

and can be illustrated by means of induction arrows. Following the convention by Parkinson (1962), the complex values $\mathrm{A}$ and $\mathrm{B}$ are drawn in opposite direction of $B_{x}$ and $B_{y}$ for the selected frequency. Therefore, the real arrow is pointing towards the better conductive structure. Real and imaginary arrows are sensitive to lateral conductivity contrasts, which is demonstrated in Fig. 6 with real and imaginary arrows for two periods of $512 \mathrm{~s}$ and $4096 \mathrm{~s}$. For the shorter period, the real arrows indicate mainly the coastline, but prominent anomalies are also reflected. Note that the shallow and not very conducting Baltic Sea $(1 \mathrm{~S} / \mathrm{m}$ to $0.1 \mathrm{~S} / \mathrm{m})$ in contrast to the deep ocean does not show coast effects at this period. With increasing penetration depth, as can be seen for the longer period, responses are smoothed and spatially expanded, due to the averaging effect of increased penetration depth i.e. due to larger volume of induction space. The coastline is now already influencing induction vectors at the distance of several hundred kilometres from the coast. Note Arora et al. (1997, 1998) for corresponding discussion of induction arrow behaviour from magnetometer array data in northeast Brazil. In the Fennoscandian Shield, induction effects of the coastline and adjacent anomalies superimpose. Imaginary arrows change with increasing period from antiparallel to parallel orientation at 2-D conductivity structures (e.g. parts of the Norwegian coastline, central Finland), diminishing at the period where the inductive response is maximal effective (maximum of real part arrow). The empirical estimate of the longitudinal conductance $G=5 * 10^{4}\left(T_{c}\right)^{1.2}$ in units of Sm by Rokityansky (1982, his formula 6.63') has been reconfirmed; e.g. the southern Finland conductor with $T_{c} \approx 2000 \mathrm{~s}$ yields a value $G=4.6 * 10^{8} \mathrm{Sm}$, which corresponds to a width of $46 \mathrm{~km}$ for a total conductance of 10000 S (cf. Fig. 3). Close to arbitrarily 3-D structures, orientations between real and imaginary arrows deviate (e.g. northern Lapland anomalies).

Magnetotelluric transfer function between the horizontal electric and magnetic field is described by the impedance tensor $\underline{\underline{\mathbf{Z}}}$ with its elements $Z_{i j}$ in the form

$$
\left(\begin{array}{c}
E_{x} \\
E_{y}
\end{array}\right)=\left(\begin{array}{ll}
Z_{x x} & Z_{x y} \\
Z_{y x} & Z_{y y}
\end{array}\right)\left(\begin{array}{c}
B_{x} \\
B_{y}
\end{array}\right) .
$$

This response function can be illustrated by apparent re- 


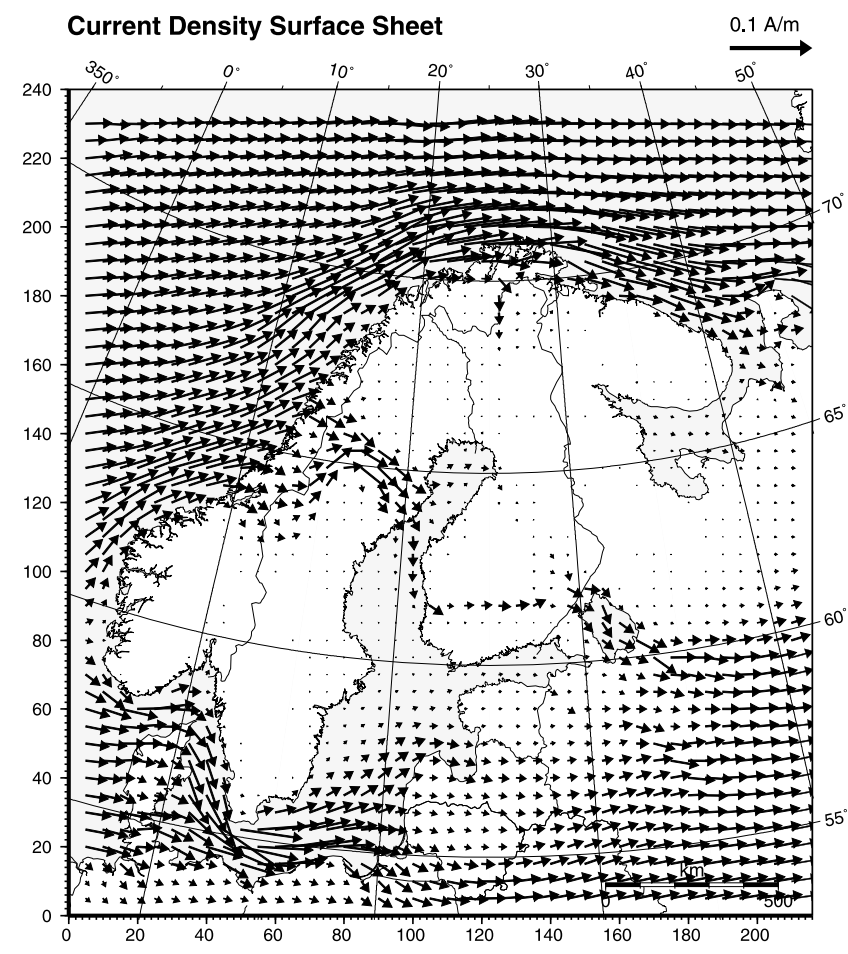

Fig. 5(a). Induced current density in the top sheet ( $0 \mathrm{~km}$ depth).

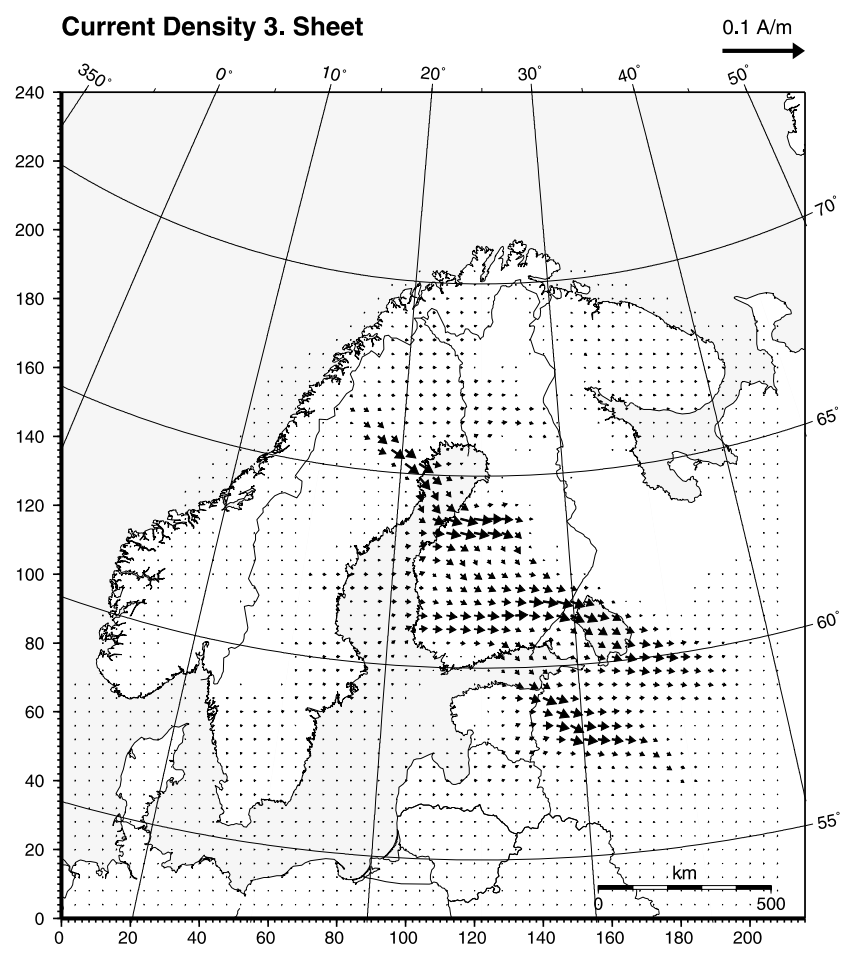

Fig. 5(c). Induced current density in the third sheet at $45 \mathrm{~km}$ depth.

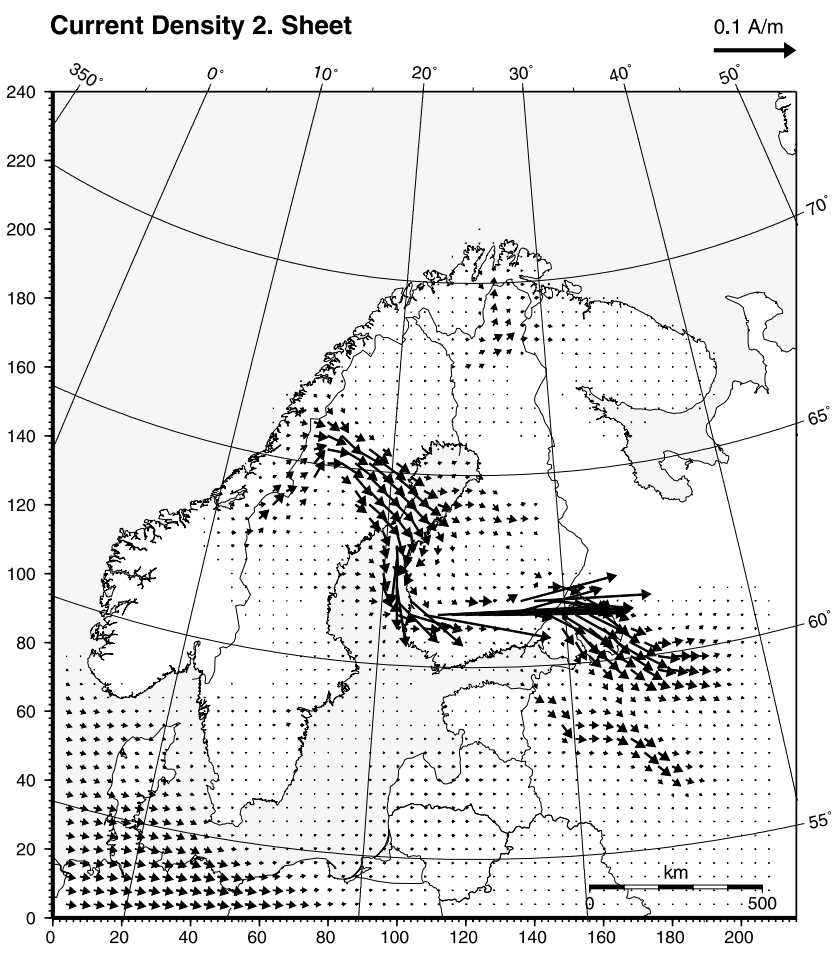

Fig. 5(b). Induced current density in the second sheet at $20 \mathrm{~km}$ depth. Vectors indicate the horizontal current density induced by plane wave excitation (magnetic field from north) for a period of 2048 s. Elongated bands of conductors are reflected in the Baltic Shield. Abscissa and ordinate units represent model cells of $10 \mathrm{~km}$ base length. sistivity $\rho_{a i j}=\mu_{0} \omega^{-1}\left|Z_{i j}\right|^{2}$, which gives the resistivity of an equivalent halfspace, and its argument, phase angle $\phi_{i j}=\arg \left(Z_{i j}\right)$. In Fig. 7 upper left and right panel, the effective apparent resistivity $\rho_{\text {adet }}=\mu_{0} \omega^{-1}\left|Z_{\text {det }}\right|$, referring to the determinant average of the impedance $Z_{\text {det }}=$ $Z_{x x} * Z_{y y}-Z_{y x} * Z_{x y}$, and its phase $\phi_{d e t}=\arg \left(Z_{d e t}\right) / 2$ are presented for a period of $2048 \mathrm{~s}$. The conductivity structure (Fig. 3) is widely resolved, even sharp boundaries of conductors can be identified. Areas of screened penetration depth are pronounced. Along the coastline, remnants of B-polarisation (oscillation at conductivity contrasts) remain visible in terms of overestimated resistivity on the shield. Those polarisation effects are clearly visible for $\rho_{a x y}$ and $\rho_{a y x}$ (not shown here) and even local areas with phase values out of quadrant occur at complex 3-D structures, which is mostly not the case in determinant representation. The corresponding phase covers a wide range from about ten degrees on the ocean, which screens electromagnetic penetration, up to about $60^{\circ}$ in high resistive parts of the shield. Crustal anomalies are not well pronounced in phase value contrasts at $2048 \mathrm{~s}$, which is more obvious at shorter periods.

For inhomogeneous source fields, the basic relations of response functions are no longer purely determined by the internal conductivity structure of the system 'Earth'-instead the external source current system is affecting responses as well. For a 1-D Earth, the basic relation of the impedance $\mathbf{E}(\omega, k)=Z(\omega, k) \mathbf{B}(\omega, k)$ is always valid in the wavenumber domain, explicitly describing external sources by wavenumber $k$. Unbiased responses are obtained only for small wavenumber, if the quasi-uniform source field condi- 

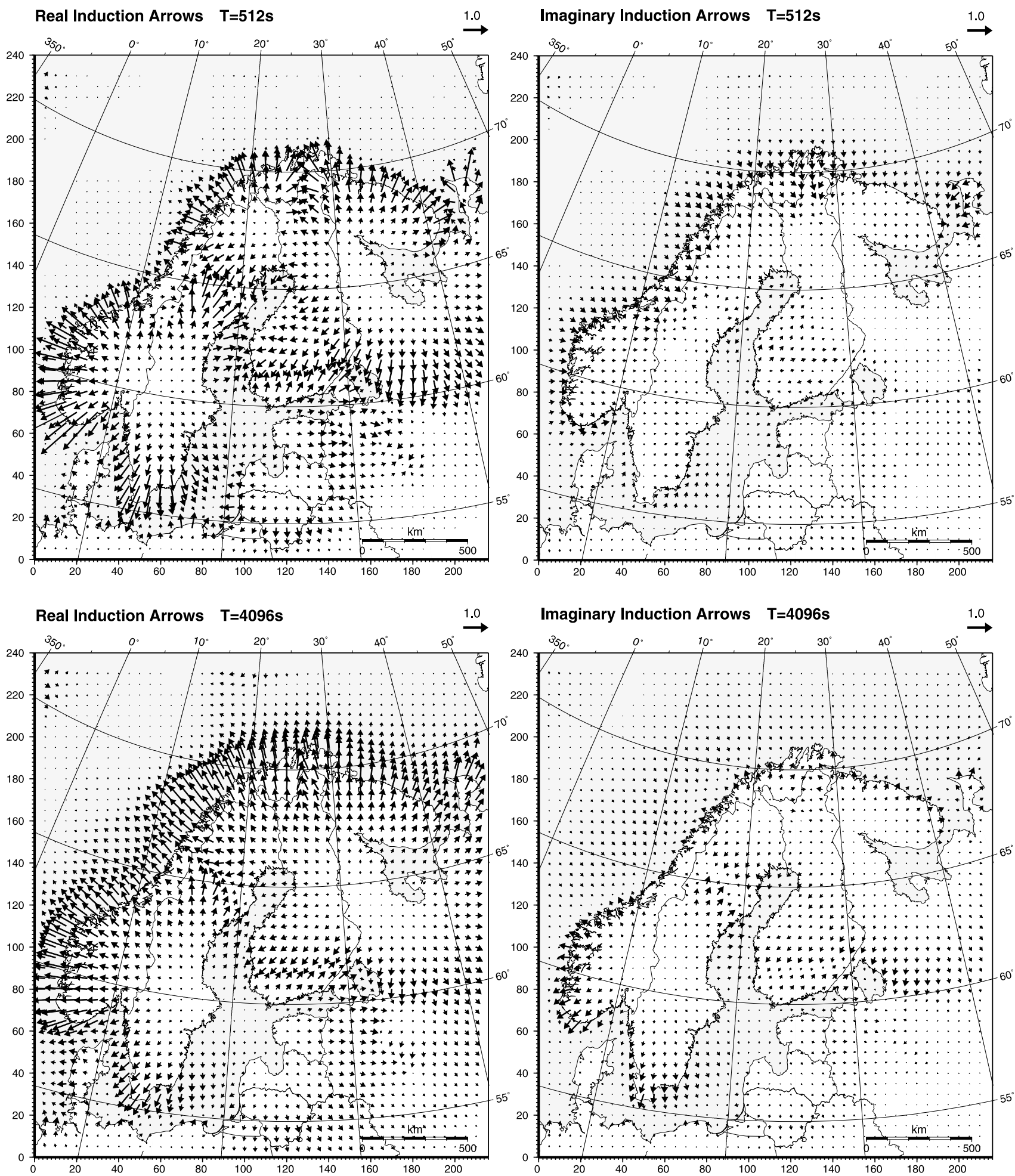

Fig. 6. Reversed induction arrows (real arrows pointing towards conductors): Real and imaginary arrows for a period of $512 \mathrm{~s}$ in the upper left and right panel; real and imaginary arrows for a period of $4096 \mathrm{~s}$ in the lower left and right panel. Induction arrows point out lateral conductance contrasts, which are effective for the two different penetration depths. Abscissa and ordinate units represent model cells of $10 \mathrm{~km}$ base length.

tion $k|C| \ll 1$ is valid. In space domain, the impedance relation using $Z=i \omega C$ reads as 2 -D convolution (symbol $* *)$

$$
\begin{aligned}
& E_{x}(\omega, x, y)=+i \omega\left(G(\omega, x, y) * * B_{y}(\omega, x, y)\right) \\
& E_{y}(\omega, x, y)=-i \omega\left(G(\omega, x, y) * * B_{x}(\omega, x, y)\right)
\end{aligned}
$$

with convolution kernel

$$
G(\omega, x, y)=\frac{1}{4 \pi^{2}} \iint_{-\infty}^{\infty} C(\omega, k) e^{i \mathbf{k} \mathbf{r}_{d}} d k_{x} d k_{y}
$$

wavenumber vector $\mathbf{k}=\left(k_{x}, k_{y}\right)$ and space vector $\mathbf{r}=$ $(x, y)$. This convolution can be expressed by a series expansion (Schmucker, 1980, also Dmitriev and Berdichevsky, 
Plane Wave: Apparent resistivity

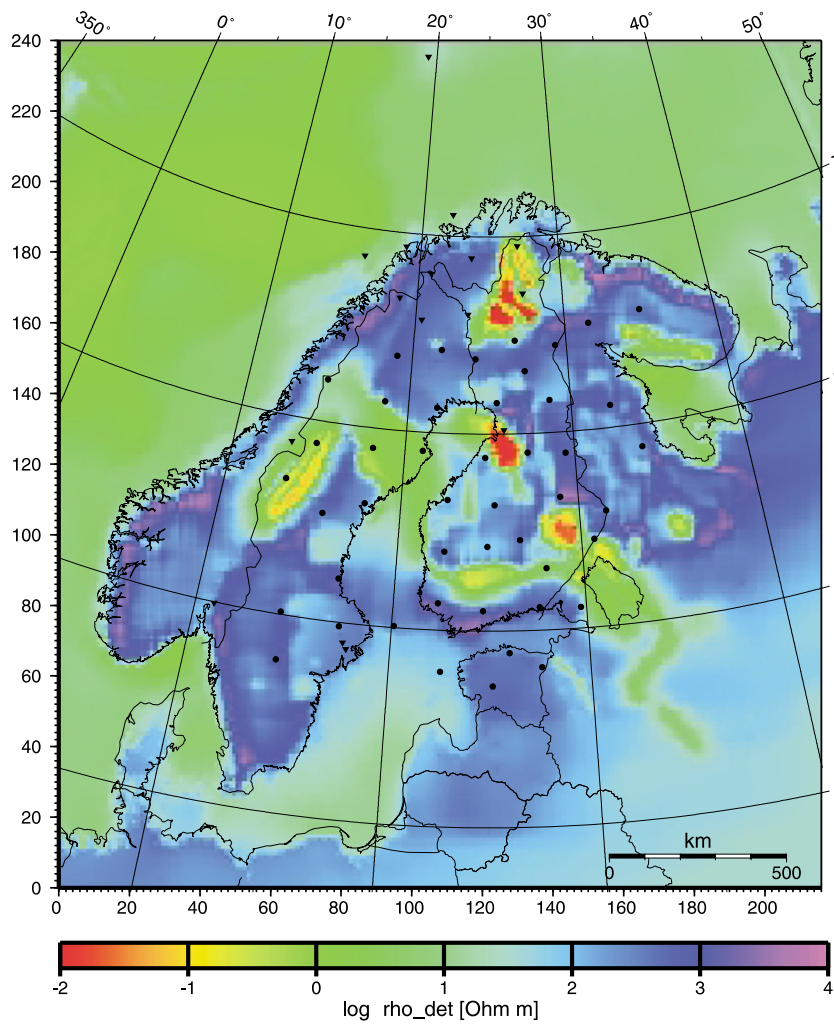

JET minus PW: Apparent Resistivity

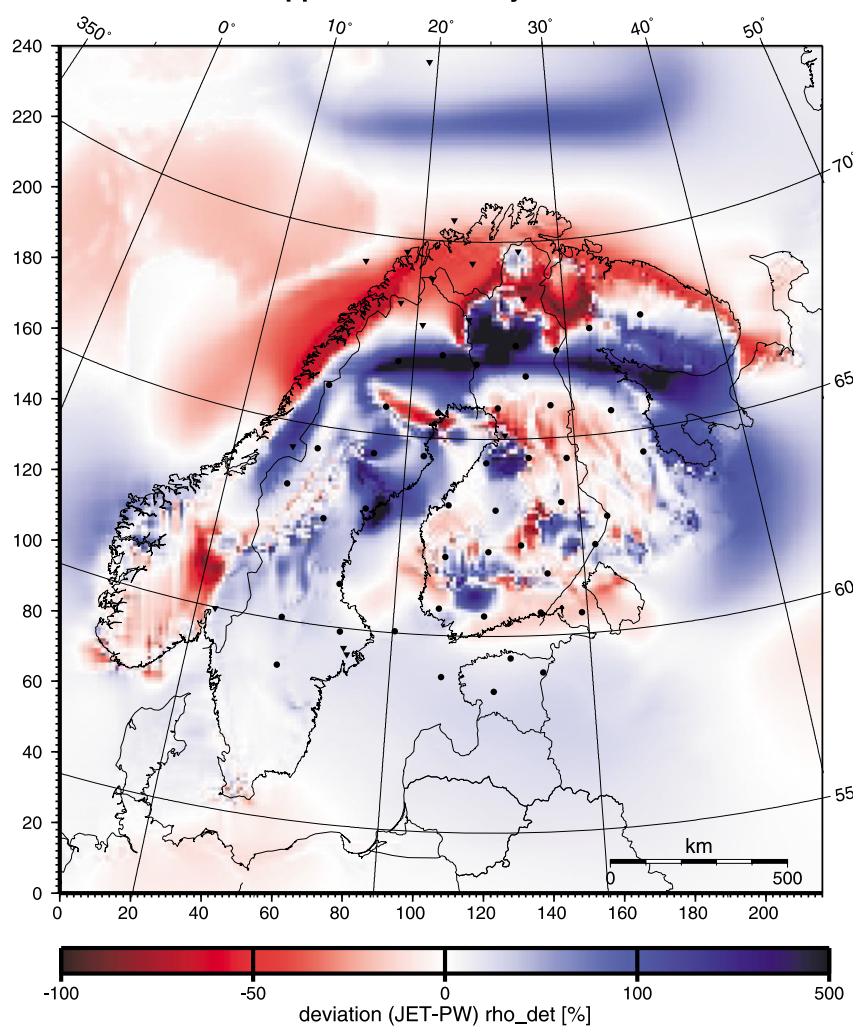

\section{Plane Wave: Phase}

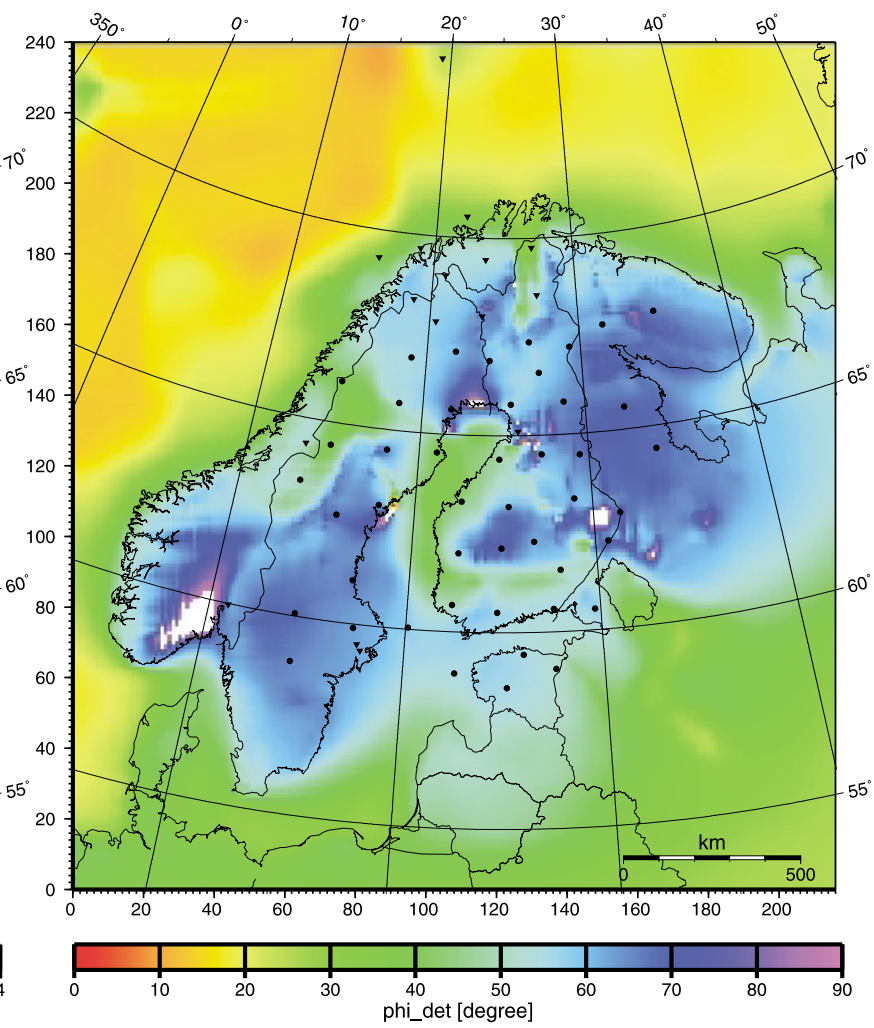

Jet Excitation: Phase

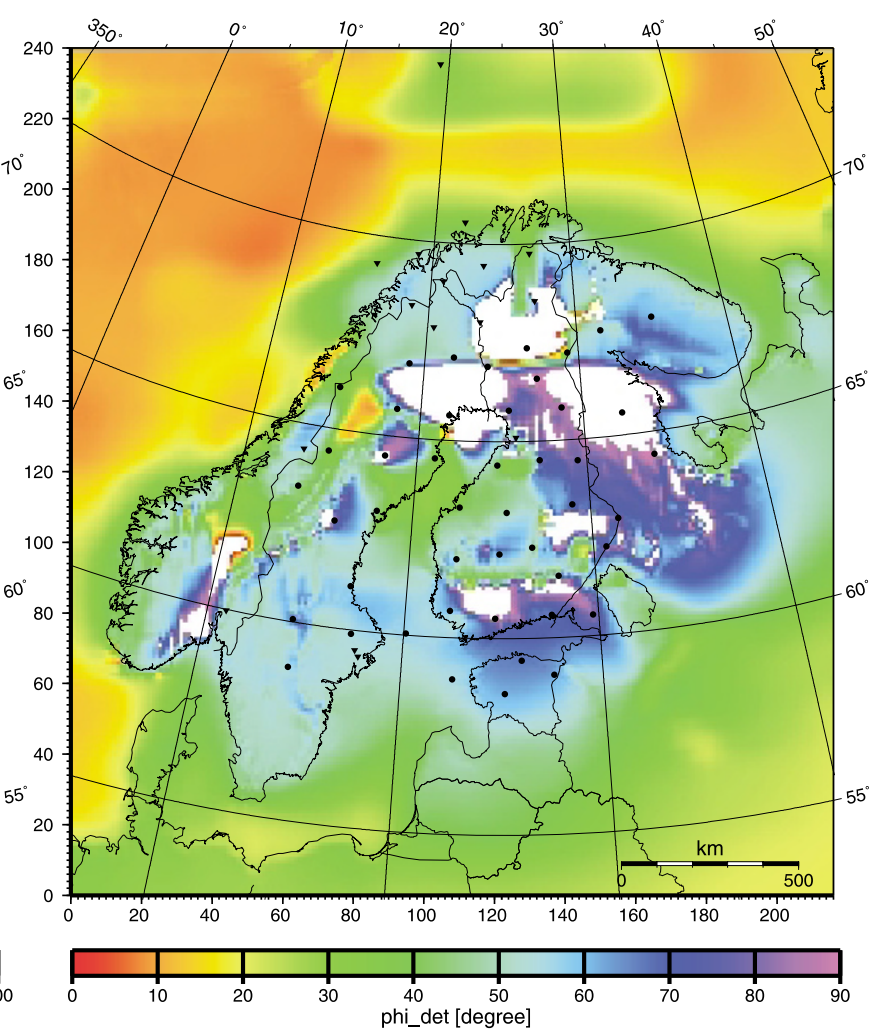

Fig. 7. For plane wave excitation, effective apparent resistivity and phase are presented in the upper left and right panel. The lower left panel shows the relative difference in apparent resistivity for the electrojet prototype model minus plane wave response. Red/blue areas indicate an under-/overestimation of 'true' plane wave apparent resistivity by electrojet excitation. The lower right panel illustrates the phase response for the electrojet source model, white areas are out-of-phase, with phase values larger $90^{\circ}$ leaving the first quadrant. Source effects turn out to behave in a very complicated manner. Instead of reflecting only the source model geometry of Fig. 4, they are strongly perturbed by the internal conductivity structure. All model responses are calculated for a period of $2048 \mathrm{~s}$ - source effect pattern do change considerably with period. Abscissa and ordinate units represent model cells of $10 \mathrm{~km}$ base length. 

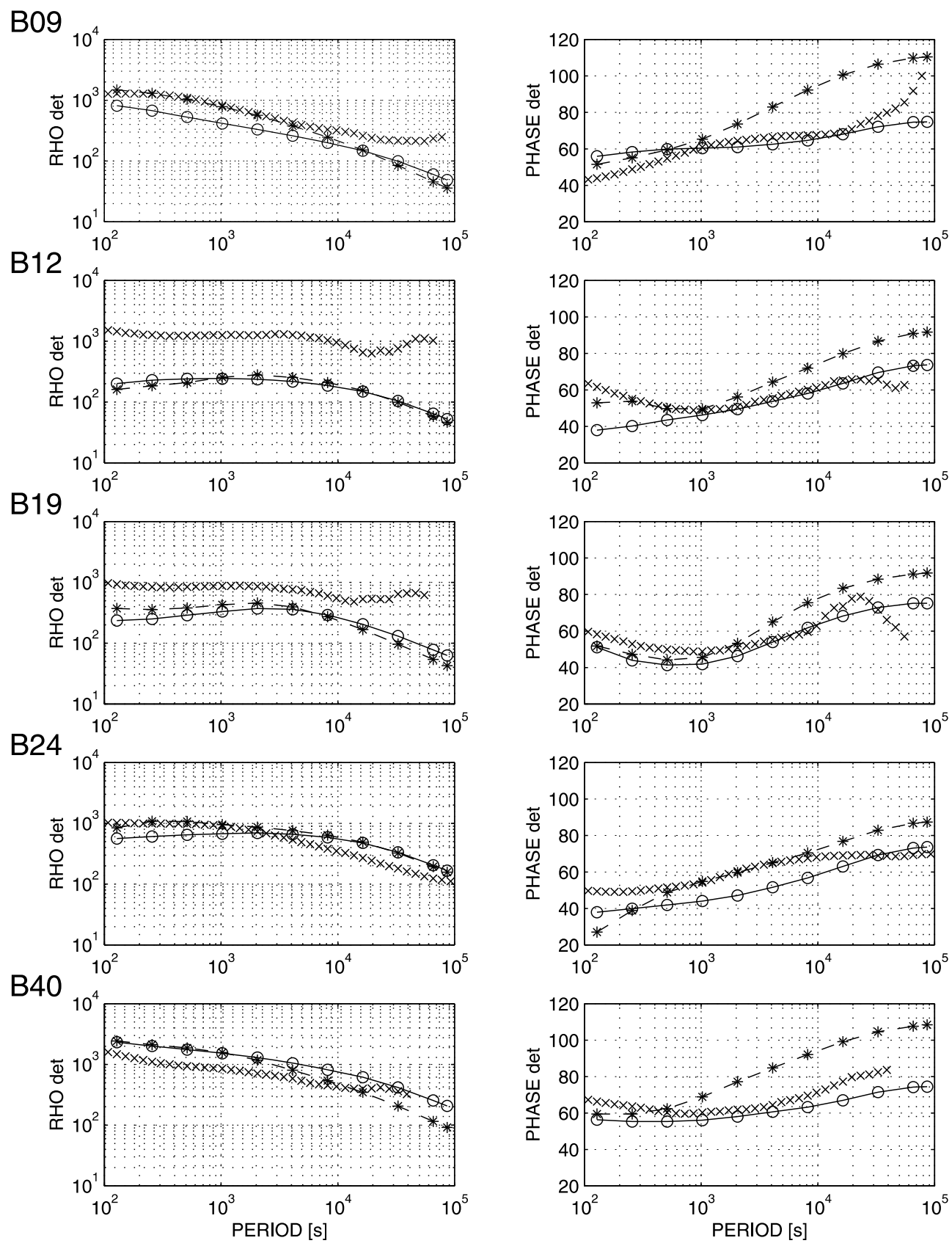

Fig. 8. Effective apparent resistivity (left) and phase (right) for 5 exemplary BEAR sites of different regions: Experimental data robust processed by Varentsov et al. (2002) are indicated by crosses, plane wave multisheet modelling responses by solid lines (open circles), electrojet modelling responses by dashed lines (filled asterisks). The a-priori conductance model is able to predict the general behaviour of most of the experimental BEAR sites; source effects might behave in various ways.

1979), showing the validity of the basic relation $\mathbf{E}(\omega, \mathbf{r})=$ $Z(\omega) \mathbf{B}(\omega, \mathbf{r})$ in space domain only for constant or linear variation of $B$ and $E$ in the vicinity (magnitude of penetration depth) of the sounding station in question. The condition of linearity is in equivalence with the quasi-uniform source field condition. Otherwise, higher (even) order correction terms have to be added. In the following, the significance of those correction terms or, in other words, the source effects produced by neglecting correction terms, will be demonstrated for a polar electrojet model. In order to estimate transfer functions (e.g. to determine the complete impedance tensor), excitation by at least two polarisations is required. Attempts with two jet sources at different locations but parallel jet axis-orthogonal jet currents are unrealistic_-yielded partly unstable responses due to a bad conditioning of those two polarisations. Instead, in analogy to data processing, which is stacking events of different source field excitation (mainly plane wave events, but inhomogeneous sources do also occur) the electrojet model has been superimposed to one of two plane wave polarisations. The scaling between the jet field and plane wave background field is controlling the intensity and development of source effects. After several tests for different ratios between the normal magnetic field below the jet centre and the back- 
Phase difference: Experiment - Model (without asthenosphere)
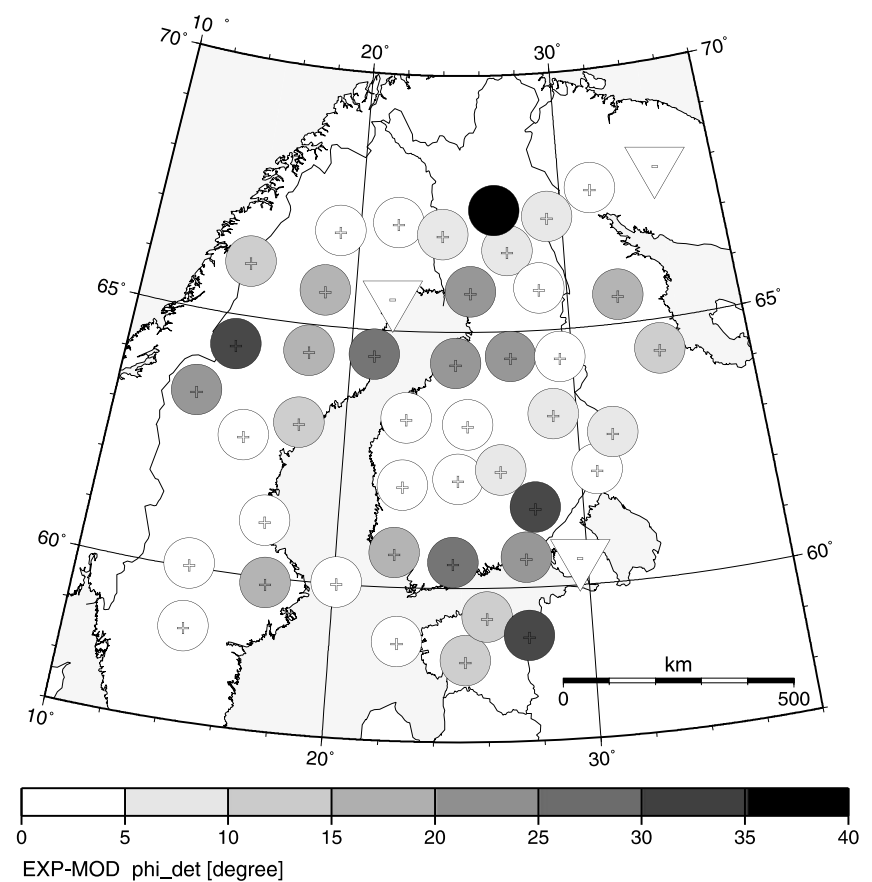

EXP-MOD phi_det [degree]

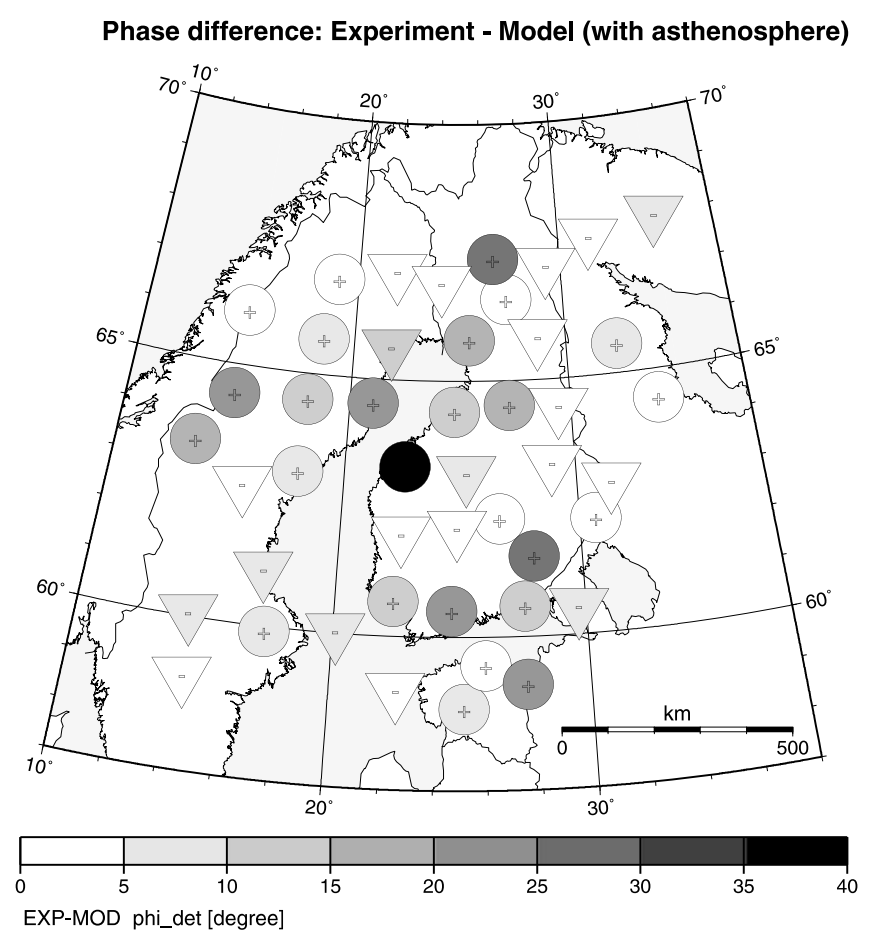

Fig. 9. Differences of experimental effective phase minus modeled phase for a period of $2048 \mathrm{~s}$ are shown, in the left panel for the standard normal model without asthenosphere (Table 2) and in the right panel for a modified normal model with an asthenospheric layer between $200 \mathrm{~km}$ and $300 \mathrm{~km}$. Positive differences are represented by circles with plus symbol, indicating missing conductance in the normal model. Negative differences are shown by inverted triangles and with minus symbol inside. The bias for the standard normal model could be removed by the modified normal model with increased upper mantle conductivity - an indication for an electrical asthenosphere.

ground field, a ratio of $20(1000 \mathrm{nT}$ over $50 \mathrm{nT})$ has been found to be a reasonable choice. The physical source for a plane wave background field might be any toroidal source current in the ionosphere or magnetosphere, as long as it is sufficiently distant. It shall be pointed out that not the modeled field intensity of an inhomogeneous source field, but only the field geometry (derivatives) is responsible for source effects as a consequence of free scaling (linearity of electromagnetic fields).

The phases $\phi_{\text {det }}$ of the electrojet source field, illustrated in Fig. 7 lower right panel, deviate considerably from those in the panel above, where results from plane wave modellings are shown. Areas out of phase (white), exceeding $90^{\circ}$, are typical for source effects and located on diverse parts of the Fennoscandian Shield. Some small areas could also be seen in plane wave results though less pronounced. Phases are mostly biased upwards - but in some areas, e.g. the Skellefteå anomaly in northern Sweden, phases turn out to be underestimated.

The distortion of the effective apparent resistivity $\rho_{\text {adet }}$, namely the difference between the plane wave model and the jet model response in percentage, is shown in Fig. 7 lower left panel. In red/blue coloured areas, jet responses are under-/overestimated in comparison with plane wave response. For a 1-D earth model, the pattern would be symmetric following exactly the symmetry of the source model. But here, the geometry of the external current system is often unrecognisable due to the complex internal conductivity structure. Towards long periods, source effects increase significantly with penetration depth larger than source dis- tance and the source geometry is reflected more clearly. In the area below the jet centre itself, resistivities are underestimated in the order of $50 \%$. This area is surrounded by a ring-like pattern of overestimated resistivities, extending far to the south with decreasing values. In the centre of the return currents, an area of underestimation (red coloured) is visible again. Note that this area exists also for the physical current loop model (for this conductivity model) - it is not an artifact due to the return currents in the equivalent current system. Distortions next to conductors do not behave systematically; some apparent resistivities are over-, others are underestimated. Often, sign of distortion is changing with period. It turns out that source effects cannot be simplified as function of distance from jet axis only. Conductors might be over- or underestimated, depending strongly on the local conductivity structure, on source field geometry and even on period.

Conventional electrojet source model studies (see review of Mareschal, 1986, for references) are often simplifications of line, band or Gaussian currents over a layered Earth. Resulting source effects are purely a function of distance from the jet-axis. They indicate underestimation of resistivity close to the jet centre and overestimation beyond (phase behaviour vice versa). The indirect influence of field aligned currents, limiting the jet extension and expressed here by use of an equivalent current system, is one step towards more realistic models. Realistic 3-D current systems can be replaced by equivalent current systems for induction studiesthis is an advantage which should be applied. Asymmetric jet models or models of finite length (e.g. Pirjola and 
Viljanen, 1998; Viljanen et al., 1999) demonstrate source effects no longer as a function of jet distance only, but those models are still based on 1-D earth models. Source effect studies using thin sheet heterogeneities are often based on 2-D jet models of infinite length (e.g. Agarwal and Weaver, 1990). This paper demonstrates the effect of a 3-D earth model and a 3-D source model (current loops): Source effects reflect not only source geometry, instead the local conductivity structure generates a complicate distortion pattern of under- and overestimation, which may vary significantly with period.

\section{Comparison with Experimental BEAR Data}

Modelling results are being compared with experimental BEAR data, processed by Varentsov et al. (2002). Their processing is based on approaches of robust methods and multi-site remote reference techniques, making use of the simultaneous array data. BEAR data are contaminated by distortions caused by non-uniform inducing fields, but robust processing techniques are capable to diminish distortions in transfer functions for periods up to 2-3 hours. Sokolova et al. (2002) monitored temporarily partial estimates of transfer functions for different time windows. This monitoring analysis outlined significant bias in partial processing results for specific time windows with increased source activity (inhomogeneity). Most of those distorted time windows are characterised by a considerable decrease in the quality of linear relations between electromagnetic field components (drop of coherence), giving opportunity to exclude such time windows from final processing using coherence criteria and further robust estimators. Therefore, plane wave solutions obtained through multisheet modelling are comparable with the observational BEAR data, which have been processed with robust, multisite reference technique.

However, for long periods, starting from a few thousand seconds, source effects might still exist. Indications are the considerable increase of phase for various experimental data, which often do not match the dispersion relation with apparent resistivity. Additionally, a tendency of increasing amplitude of horizontal magnetic transfer functions, which are sensitive to primary external fields, towards the polar oval supports this thesis - in contrast to modelling results. As long as these source effects are related to daily variation systems (e.g. $S_{q}^{p}$ on quiet and DP2 on disturbed days), they might dominate the majority of data events and robust processing schemes will fail to provide unbiased estimates of plane wave response.

Remember that the numerical multisheet modelling results are based on the a-priori conductivity information; new modelling results out of BEAR data will be included at a later stage. Furthermore, these are forward modelling results not based on any inversion of data. Thus they would not be expected to fit the data in detail. But they will point out where the present knowledge of the conductivity structure is able to match the observations and where not.

In Fig. 8, effective apparent resistivity and phase of experimental data (crosses) are compared with results of plane wave modelling (solid line) and electrojet excitation (dashed line). The electrojet data are not expected to explain experimental data, but examples demonstrate various phenomena of source effects. While for some sites, significant source effects in apparent resistivity do not occur over the whole period range, other sites might show source effects increasing with period. Resistivities are partly over- or underestimated in different period ranges. An almost common tendency is the overestimation of phase from electrojet source towards long periods. Experimental and synthetic plane wave data mostly correspond well to each other. Note that the experimental resistivities are not static shift corrected, therefore rather the shape than the absolute level is comparable. The fit for most of the sites is satisfying as a first order approximation, while the misfit of about one third of BEAR sites is unacceptable - in these cases, either a-priori conductance information or the multisheet simplification are not valid or data quality is problematic.

The difference in phase angle between experimental and modeled data is shown in Fig. 9 for a period of 2048 s, associated with upper mantle depth. For the normal model of Table 2, a systematically positive bias is obvious (circles dominate triangles) in the left panel. Too low phase angles of the modelling indicate missing conductance at mantle depth. Therefore, an alternative normal model including an asthenospheric layer between $200 \mathrm{~km}$ and $300 \mathrm{~km}$ with $20 \Omega \mathrm{m}$ was introduced, replacing the previously assigned $100 \Omega \mathrm{m}$. This alternative model, including a well conducting asthenosphere, results in an equally distributed pattern of under- and overestimation shown in the right panel of Fig. 9, removing the previous bias completely. Hence a strong indicator for a well conducting upper mantle has been found by means of multisheet forward modelling. The corresponding behaviour for apparent resistivity supports this tendency, but it is less clear due to static shift effects.

The distinction between an asthenospheric layer, underlayed by increasing resistivity, or continuously decreasing resistivity, cannot be decided yet. Increasing resistivity below the asthenosphere is accompanied by a relative deflation of phase at longer periods. But experimental data at those very long periods seem to be biased by source effects and consequently phase differences might be very misleading.

\section{Conclusion and Outlook}

Multisheet modelling studies of this paper are based on more realistic earth and source model. The earth model is taking detailed a-priori knowledge of the conductivity structure in the whole Fennoscandian Shield into account (Korja et al., 2002). The source model of a polar electrojet prototype consists of current loop elements, which are represented by an equivalent current system. Source effects turn out to behave in a complicated and nearly unpredictable way. Their pattern, supposed to reflect source geometry, is perturbed considerably by the internal conductivity structure and depends strongly on frequency.

However, the prototype source model used here, the simple static geometry, is still an idealised and 'extreme' case study (as all single event model studies). The use of more realistic dynamic equivalent current systems derived from experimental data is required. The BEAR array data allows to derive realistic equivalent current systems (based on Amm and Viljanen, 1999) and the multisheet code is able to model dynamic sources as well. 
BEAR data responses confirm multisheet forward modelling results based on the a-priori earth model for most of the sites, while other sites fail. Misfits indicate modifications and additional anomalies in the earth model.

The conductivity model is going to be improved by taking future modelling results of BEAR data into account. Hypothetical conductors can be included and tested by comparison of predicted responses with measured data.

The phase bias between experimental and multisheet synthetic data for the selected standard reference 1-D model could be removed by use of a better conducting reference model of $20 \Omega \mathrm{m}$ resistivity between $200 \mathrm{~km}$ and $300 \mathrm{~km}$ depth. Thus, a clear indication on a well conducting upper mantle, the possible existence of an electrical asthenosphere, is given by multisheet modelling of the Fennoscandian Shield.

Acknowledgments. The work presented in this paper was made possible through the following contracts: TMR Marie Curie fellowship (M.E.) ERBFMBICT983327 and INTAS 97-1162 of the European Commission, Academy of Finland 39222, Swedish Natural Science Research Council NFR G-AA/GU 04990-350. This work is a contribution to the EUROPROBE/SVEKALAPKO project. The authors are very grateful for fruitful cooperation within the BEAR working group and with Alexei Kuvshinov, Dmitry Avdeev and Oleg Pankratov. Dr. B. R. Arora and Dr. L. Szarka improved the manuscript by their constructive criticisms.

\section{References}

Agarwal, A. K. and J. T. Weaver, A three-dimensional numerical study of induction in southern India by an electrojet source, Phys. Earth Planet. Int., 60, 1-17, 1990.

Amm, O. and A. Viljanen, Ionospheric disturbance magnetic field continuation from the ground to the ionosphere using spherical elementary current systems, Earth Planets Space, 51, 431-440, 1999.

Arora, B. R., A. Rigoti, I. Vitorello, A. L. Padilha, N. B. Trivedi, and F. H. Chamalaun, Electrical imaging of the intracratonic Parnaiba Basin, north-northeast Brazil, J. Geomag. Geoelectr., 49, 1631-1648, 1997.

Arora, B. R., A. Rigoti, I. Vitorello, A. L. Padilha, N. B. Trivedi, and F. H. Chamalaun, Magnetometer array study in north-northeast Brazil: Conductivity image building and functional induction modes, Pure a. Applied Geophys., 152, 349-375, 1998.

Avdeev, D. B., A. V. Kuvshinov, O. V. Pankratov, and G. A. Newman, Highperformance three-dimensional electromagnetic modeling using modified Neumann series. Wide-band numerical solution and examples, $J$. Geomag. Geoelectr., 49, 1519-1539, 1997.

Avdeev, D. B., A. V. Kuvshinov, O. V. Pankratov, and G. A. Newman, Three-dimensional frequency-domain modeling of airborne electromagnetic responses, Exploration Geophysics, 29, 1-9, 1998.

Avdeev, D. B., A. V. Kuvshinov, O. V. Pankratov, and G. A. Newman, Modeling induction log responses in $3 \mathrm{D}$ geometries using integral equation approach, Second International Symposium on three-dimensional electromagnetics, University of Utah, Salt Lake City, Utah, USA, Expanded Abstracts, 99-103, 1999.

Avdeev, D. B., A. V. Kuvshinov, O. V. Pankratov, and G. A. Newman, 3-D EM modeling using fast integral equation approach with Krylov subspaces accelerator, Extended abstracts book, Volume 2, 62nd EAGE Conference \& Technical Exhibition, Glasgow, Scotland, P-183, 4 p., 2000.

Dawson, T. W. and J. T. Weaver, Three-dimensional induction in a nonuniform thin sheet at the surface of a uniformly conducting earth, Geophys. J. R. astr. Soc., 59, 445-462, 1979.

Dmitriev, V. I. and M. N. Berdichevsky, The fundamental model of magnetotelluric sounding, Proc. IEEE, 67, 1034-1044, 1979.

Fukushima, N., Electric current systems for polar substorms and their magnetic effect below and above the ionosphere, Radio Sci., 6, 269-275, 1971.

Fukushima, N., Generalized theorem for no ground magnetic effect of vertical currents connected with Pedersen currents in the uniform-conductivity ionosphere, Rep. Ionos. Space Res. Japan, 30, 35-40, 1976.
Garcia, X., A. D. Chave, and A. G. Jones, Robust Processing of Magnetotelluric Data from the Auroral Zone, J. Geomag. Geoelectr., 49, 14511468, 1997.

Gharibi, M., T. Korja, and L. B. Pedersen, Magnetotelluric soundings across the Scandinavian Caledonides, Jämtland, Sweden, in Electromagnetic Studies of the Continental Crust in Sweden, edited by M. Gharibi, Acta Universitatis Upsaliensis. Comprehensive Summaries of Uppsala Dissertations from the Faculty of Science and Technology, Uppsala, Sweden, 513, 1-50, 2000.

Gorbatschev, R. and S. Bogdanova, Frontiers in the Baltic Shield, Precambrian Res., 64, 3-21, 1993.

Greenbaum, A., Iterative Methods for Solving Linear Systems, Society for Industrial and Applied Mathematics, Philadelphia, 1997.

Hjelt, S.-E. and S. Daly, SVEKALAPKO, Evolution of Palaeoproterozoic and Archaean Lithosphere, in EUROPROBE 1996-Lithosphere Dynamics Origin and Evolution of Continents, edited by D. G. Gee and H. J. Zeyen, pp. 57-67, published by the EUROPROBE Secretariate, Uppsala University, 1996.

Jones, A. G., Geomagnetic induction studies in Scandinavia. II Geomagnetic depth sounding, induction vectors and coast effect, J. Geophys., 50, 23-36, 1981.

Jones, A. G., The electrical structure of the lithosphere and asthenosphere beneath the Fennoscandian shield, J. Geomag. Geoelectr., 35, 811-827, 1983.

Kaikkonen, P., Thin-Sheet Modelling for Deep Electromagnetic Studies in the Fennoscandian Shield, in Deep Electromagnetic Exploration, edited by K. K. Roy, S. K. Verma, and K. Mallick, pp. 365-386, Narossa Publishing House, New Delhi, India, 1998.

Korja, T., S.-E. Hjelt, P. Kaikkonen, K. Koivukoski, T. M. Rasmussen, and R. G. Roberts, The geoelectric model of the POLAR profile, Northern Finland, Tectonophys., 162, 113-133, 1989.

Korja, T. and S.-E. Hjelt, Electromagnetic studies in the Fennoscandian Shield-electrical conductivity of Precambrian crust, Phys. Earth Planet. Inter., 81, 107-138, 1993.

Korja, T. and K. Koivukoski, Crustal conductors of the SVEKA Profile in the Early Proterozoic Fennoscandian (Baltic) Shield, Finland, Geophys. J. Int., 116, 173-197, 1994.

Korja, T., Electrical Conductivity of the Lithosphere-Implications for the Evolution of the Fennoscandian Shield, Geophysica, 33(1), 17-50, 1997.

Korja, T. and S.-E. Hjelt, The Fennoscandian Shield: A treasury box for deep electromagnetic studies, in Deep Electromagnetic Exploration, edited by K. K. Roy, S. K. Verma, and K. Mallick, pp. 31-73, Narossa Publishing House, New Delhi, India, 1998.

Korja, T., M. Engels, A. A. Zhamaletdinov, A. A. Kovtun, N. A. Palshin, M. Yu. Smirnov, A. D. Tokarev, V. E. Asming, L. L. Vanyan, I. L. Vardaniants, and the BEAR Working Group, Crustal conductivity in Fennoscandia - a compilation of a database on crustal conductance in the Fennoscandian Shield, Earth Planets Space, 54, this issue, 535-558, 2002.

Korsman, K., T. Korja, M. Pajunen, P. Virransalo, and the GGT/SVEKA Working Group, The GGT/SVEKA Transect: Structure and Evolution of the Continental Crust in the Palaeoproterozoic Svecofennian Orogen in Finland, International Geology Review, 41, 4, 287-333, 1999.

Kovtun, A. A., S. A. Vagin, I. L. Vardaniants, N. P. Legenkova, N. I. Uspenskiy, and M. Yu. Smirnov, Structure of the crust and upper mantle by the MT soundings on the profile Murmansk-Suoyarvy-Vyborg, Rossiyaskaya geofizika, 11-12, 57-67, 1998 (in Russian).

Kuvshinov, A. V., D. B. Avdeev, O. V. Pankratov, and S. A. Golyshev, Modeling EM fields in 3D spherical earth using integral equation approach, The Second International Symposium on 3D electromagnetics, University of Utah, Salt Lake City, Utah, USA, Expanded Abstracts, 84-88, 1999.

Mareschal, M., Modelling of natural sources of magnetospheric origin in the interpretation of regional induction studies: A review, Surveys in Geophysics, 8, 261-300, 1986.

McKirdy, D. McA., J. T. Weaver, and T. W. Dawson, Induction in a thin sheet of variable conductance at the surface of a stratified earth-II. Three-dimensional theory, Geophys. J. R. astr. Soc., 80, 177-194, 1985.

Osipova, I. L., S.-E. Hjelt, and L. L. Vanyan, Source field problems in northern parts of the Baltic Shield, Phys. Earth Planet. Inter., 53, 337342, 1989.

Pajunpää, K., Conductivity anomalies in the Baltic Shield in Finland, Geophys. J. R. astr. Soc., 91, 657-666, 1987.

Pajunpää, K., Magnetometer array studies in Finland, Acta Univ. Oul., A 205, 32 pp., 1989. 
Pankratov, O. V., Electromagnetic field modeling in presence of subsurface and deep inhomogeneities, Ph.D. Thesis, Institute of Physics of the Earth, Moscow, 162 pp., 1991 (in Russian).

Pankratov, O. V., D. B. Avdeev, and A. V. Kuvshinov, Electromagnetic field scattering in a heterogeneous earth: A solution to the forward problem, Physics of the Solid Earth, 31, 201-209, 1995 (English edition).

Pankratov, O. V., A. V. Kuvshinov, and D. B. Avdeev, High-performance three-dimensional electromagnetic modeling using modified Neumann series. Anisotropic case, J. Geomag. Geoelectr., 49, 1541-1547, 1997.

Parkinson, W. D., The influence of continents and oceans on geomagnetic variation, Geophys. J. R. astr. Soc., 6, 441-449, 1962.

Pirjola, R., On magnetotelluric source effects caused by an auroral electrojet system, Radio Sci., 27(4), 463-468, 1992.

Pirjola, R. and A. Viljanen, Complex image method for calculating electric and magnetic fields produced by an auroral electrojet of finite length, Ann. Geophys., 16, 1434-1444, 1998.

Price, A. T., The induction of electric currents in non-uniform thin sheets and shells, Q. J. Mech. appl. Math., 2, 283-310, 1949.

Rasmussen, T. M., R. G. Roberts, and L. B. Pedersen, Magnetotellurics along the Fennoscandian Long Range Profile, Geophys. J. R. astr. Soc., 89, 799-820, 1987.

Rasmussen, T. M., Magnetotellurics in southwestern Sweden: evidence for electrical anisotropy in the lower crust, J. Geophys. Res., 93, 7897-7907, 1988.

Rokityansky, I. I., Geoelectromagnetic Investigation of the Earth's Crust and Mantle, Springer Verlag, New York, 1982.

Schmucker, U., Anomalies of geomagnetic variations in the southwestern United States, Bull. Scripps, Institution of Oceanography, University of California, 13, 1-165, 1970.

Schmucker, U., Induktion in geschichteten Halbräumen durch inhomogene Felder, Protokoll Koll. Elektromagnetische Tiefenforschung, BerlinLichtenrade, 197-210, 1980 (in German).

Schmucker, U., Electromagnetic induction in thin sheets: integral equations and model studies in two dimensions, Geophys. J. Int., 121, 173-190, 1995.

Singer, B. Sh., Method for solution of Maxwell's equations in non-uniform media, Geophys. J. Int., 120, 590-598, 1995.

Singer, B. Sh. and E. B. Fainberg, Electromagnetic induction in nonuniform thin layers, IZMIRAN, Moscow, 234 pp., 1985 (in Russian).

Singer, B. Sh. and E. B. Fainberg, Generalization of the iterative-dissipative method for modeling electromagnetic fields in nonuniform media with displacement currents, J. Applied Geophysics, 34, 41-46, 1995.

Singer, B. Sh. and E. B. Fainberg, Fast and stable method for 3-D modelling of electromagnetic field, Exploration Geophysics, 28, 130-135, 1997.
Singer, B. Sh., A. Mezzatesta, and T. Wang, 3D IDM modeling of EM field, The Second International Symposium on 3D electromagnetics, University of Utah, Salt Lake City, Utah, USA, Expanded Abstracts, 29-33, 1999.

Sokolova, E. Yu., Iv. M. Varentsov, and BEAR Working Group, Investigation and elimination of polar magnetotelluric source distortions in the BEAR project transfer functions, Earth Planets Space, 2002 (to be submitted).

Vanyan, L. L., T. A. Demidova, N. A. Palshin, A. A. Zhamaletdinov, Yu. I. Kuksa, P. Kaikkonen, and T. Korja, Interpretation of the deep DC soundings in the northeastern Baltic Shield, Phys. Earth Planet. Inter., 54, 149-155, 1989.

Vanyan, L. L. and V. A. Kouznetsov, A crustal conducting layer in Central Finland: myth or reality?, Fizica Zemli, 3, 62-64, 1999 (in Russian).

Varentsov, Iv. M., E. Yu. Sokolova, E. R. Martanus, K.V. Nalivaiko, and BEAR Working Group, Estimation of MT and GDS transfer functions in the Baltic Electromagnetic Array Research (BEAR), Earth Planets Space, 2002 (to be submitted).

Vasseur, G. and P. Weidelt, Bimodal electromagnetic induction in nonuniform thin sheets with an application to the northern Pyrenean induction anomaly, Geophys. J. R. astr. Soc., 51, 669-690, 1977.

Viljanen, A., Source Effect on Geomagnetic Induction Vectors in the Fennoscandian Auroral Region, J. Geomag. Geoelectr., 48, 1001-1009, 1996.

Viljanen, A. and L. Häkkinen, IMAGE magnetometer network, in SatelliteGround Based Coordination Sourcebook, edited by M. Lockwood, M. N. Wild, and H. J. Opgenoorth, ESA publications, SP-1198, 111-117, 1997.

Viljanen, A., R. Pirjola, and O. Amm, Magnetotelluric source effect due to $3 \mathrm{D}$ ionospheric current systems using the complex image method for 1D conductivity structures, Earth Planets Space, 51, 933-945, 1999.

Weaver, J. T., Mathematical Methods for Geo-electromagnetic Induction, Research Studies Press LTD, 1994.

Yegorov, I. V., E. L. Chernyak, N. A. Palshin, T. A. Demidova, and P. Kaikkonen, Numerical thin-sheet modelling of telluric field distortions by hybrid technique. I Theory and an example for the Baltic Shield, Phys. Earth Planet. Inter., 33, 56-63, 1983.

Zhdanov, M. S., V. I. Dmitriev, G. Hursan, and S. Fang, Quasi-analytical approximations and series in 3-D electromagnetic modeling, The Second International Symposium on 3D electromagnetics, University of Utah, Salt Lake City, Utah, USA, Expanded Abstracts, 16-21, 1999.

M. Engels (e-mail: Martin.Engels@geofys.uu.se), T. Korja, and the BEAR Working Group 